
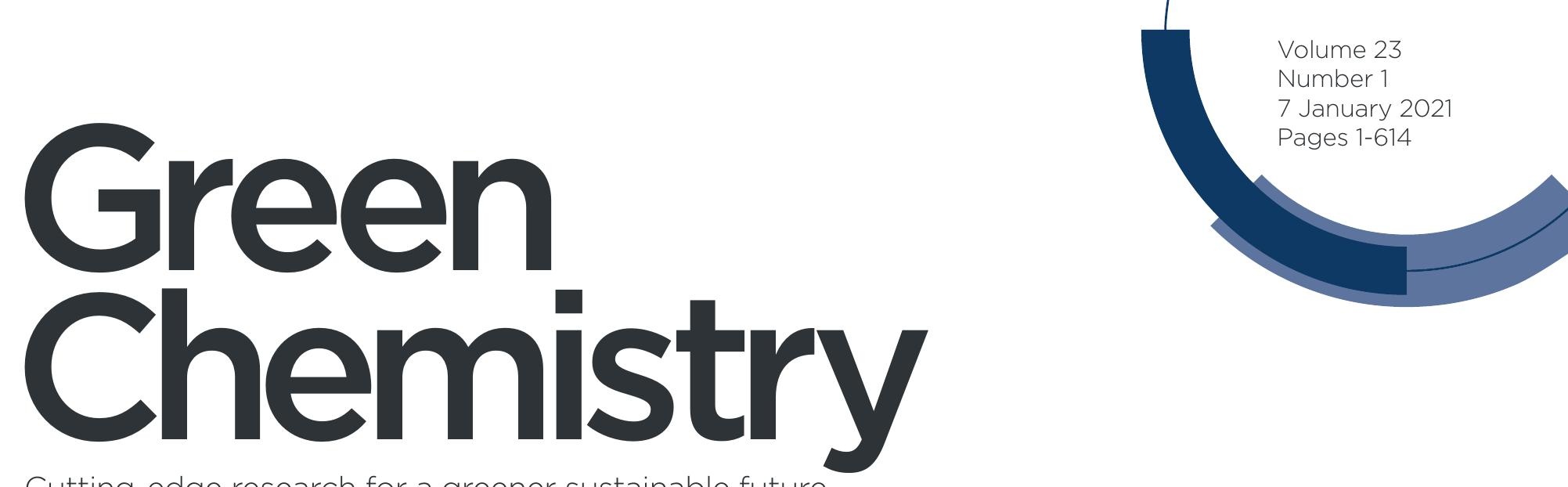

Cutting-edge research for a greener sustainable future

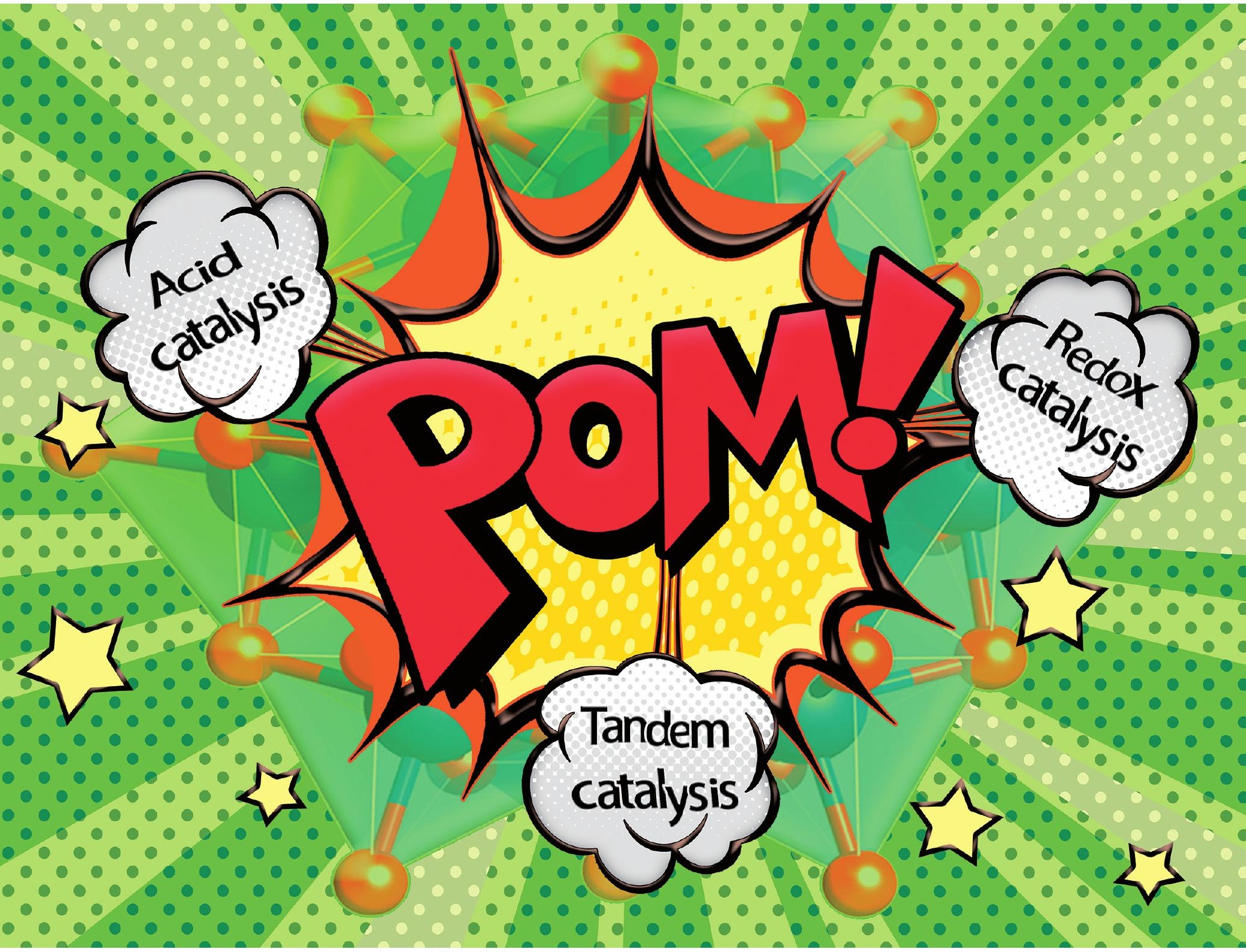

ISSN 1463-9262

ROYAL SOCIETY OF CHEMISTRY
Javier Pérez-Ramírez, Ning Yan et al.

Biomass valorisation over polyoxometalate-based catalysts 


\section{D) Check for updates}

Cite this: Green Chem., 2021, 23, 18

\title{
Biomass valorisation over polyoxometalate-based catalysts
}

\author{
Jiawei Zhong, ${ }^{a}$ Javier Pérez-Ramírez (D) *a,b and Ning Yan (D)*a
}

The efficient utilization of biomass, the only globally available, renewable and abundant carbon-neutral source, is of high significance in green and sustainable chemistry. Polyoxometalates (POMs) and POMbased composites have been widely applied in green catalytic reactions, due to their tunable Brønsted/ Lewis-acidity and redox properties enabling high reactivity in a wide range of chemical transformations. This review covers recent advances in the chemocatalytic conversion of biomass into chemicals and fuels over POMs and POM-metal composites. For biomass valorisation over POMs, the advances of acid catalysis including hydrolysis, dehydration, etherification, alcoholysis, transesterification and esterification are summarised. Furthermore, applications in chemical oxidation for the synthesis of organic acids and furan chemicals are discussed. For biomass valorisation over metal-POM composites, an overview of tandem reactions (e.g. hydrolysis-hydrogenation, hydrolysis-oxidation, and hydrogenolysis-hydrodeoxygenation) is highlighted. The future prospects of biomass valorisation over POM-based catalysts are finally presented.

Received 21st September 2020 Accepted 2nd November 2020 DOI: $10.1039 / \mathrm{dOgc03190a}$ rsc.li/greenchem

\section{Introduction}

Since the industrial revolution, the ever-increasing consumption of fossil carbon resources including coal, crude oil and natural gas for energy and chemicals has resulted in enormous emissions of greenhouse gases (GHGs) into the atmosphere. The increasing demand for resources, the diminishing finite fossil reserves as well as the urgent need to reduce GHG emissions have driven the innovative development of alternative

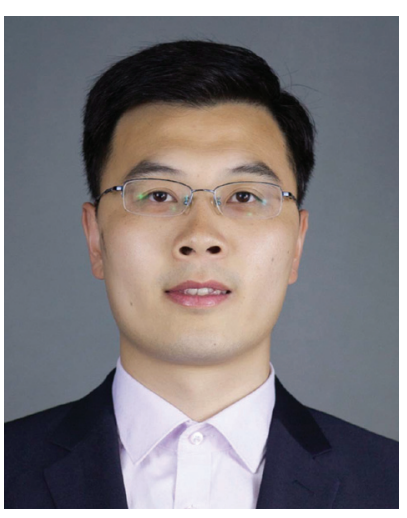

Jiawei Zhong
Jiawei Zhong completed his Ph.D research in Dalian Institute of Chemical Physics, Chinese Academy of Sciences, and received his $P h D$ degree in industrial catalysis from Dalian University of Technology in 2019, under the supervision of Professor Zhongmin Liu, Chunshan Song and Yingxu Wei. Then he worked as a postdoctoral fellow with Prof. Javier Pérez-Ramirez and Ning Yan at the National University of Singapore. His research interests include heterogeneous catalysis and catalytic materials, catalytic valorization of biomass, as well as C1 chemistry.

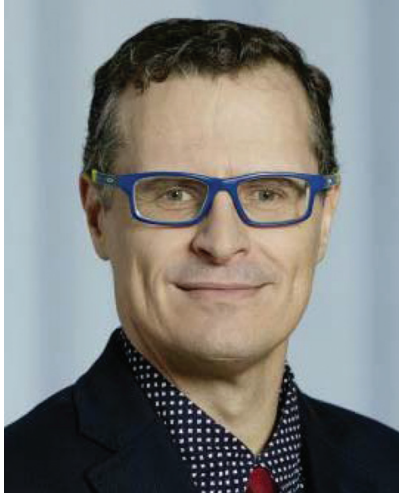

Javier Pérez-Ramírez
Javier Pérez-Ramirez holds the Chair of Catalysis Engineering at ETH Zurich. His research pursues the design of heterogeneous catalysts and reactor concepts tackling current and future energy, resource, and environmental challenges of society. He directs a National Competence Center of Research in Catalysis in Switzerland and has a visiting appointment at the National University of Singapore within the Flagship Green Energy Program. 
energy sources derived from green and sustainable feedstocks in a post-petroleum era.

Biomass, including carbohydrates, lignin, and lipids, among others, is an attractive alternative feedstock. It is the only globally available, renewable and abundant carbonneutral source. Due to the relevant debate regarding "food versus fuel", lignocellulosic biomass composed of non-edible cellulose (35-50\%), hemicelluloses (20-35\%) and lignin (10-25\%) has attracted significant attention. A biorefinery that provides low-value/high-volume liquid fuels and low-volume/ high-value chemicals, in particular from lignocellulosic biomass, has been the subject of intense research efforts. ${ }^{1,2}$

Polyoxometalates (POMs) are a unique class of anionic polynuclear metal-oxo clusters with structural diversity at the atomic level, with their negative charge being balanced by countercations. In general, POMs are mainly classified into isopolyoxometalates $\left[\mathrm{M}_{x} \mathrm{O}_{y}\right]^{n-}$, which feature only metal and oxygen atoms $\left[\mathrm{M}=\right.$ typically high-valent $\left(\mathrm{d}^{0}\right.$ or $\mathrm{d}^{1}$ electronic configuration) group $\mathrm{V}$ and VI transition metals (e.g., Mo, W, $\mathrm{V})]$, and heteropolyoxometalates $\left[\mathrm{X}_{x} \mathrm{M}_{y} \mathrm{O}_{z}\right]^{n-}$, containing additionally a heteroelement $\mathrm{X}($ e.g., $\mathrm{Si}$ and $\mathrm{P}){ }^{3,4}$ Due to the tunable Brønsted/Lewis-acidity and redox properties, POMs and POM-based composites have long been applied in heterogeneous catalysis. ${ }^{3-5}$ In the field of catalytic biomass valorisation, POMs have been employed as environmentally benign acid or oxidation catalysts ${ }^{3,4}$ in the synthesis of renewable chemicals and fuels including platform chemicals, ${ }^{6-8}$ organic acids, furans, ${ }^{9-11}$ and biodiesels. ${ }^{12-14}$ Similarly, metal-POM composites have also been used for biomass conversion into chemicals and fuels. ${ }^{6,15,16}$

Many excellent reviews on biosourced chemicals and fuels have been published, devoted to specific feedstock such as carbohydrates, ${ }^{1,9,17}$ cellulose, ${ }^{8,18,19}$ lignin, ${ }^{20} \mathrm{C}_{5}-\mathrm{C}_{6}$ sugars, ${ }^{21,22}$ and glycerol, ${ }^{23,24}$ focusing on specific reactions such as hydrolysis, ${ }^{7,8,25-27}$ dehydration, ${ }^{21,23}$ esterification, transesterification, ${ }^{12-14}$ oxidation, ${ }^{9,10}$ hydrogenolysis, ${ }^{24,28}$ and hydrodeoxygenation, ${ }^{29,30}$ or dealing with specific catalytic

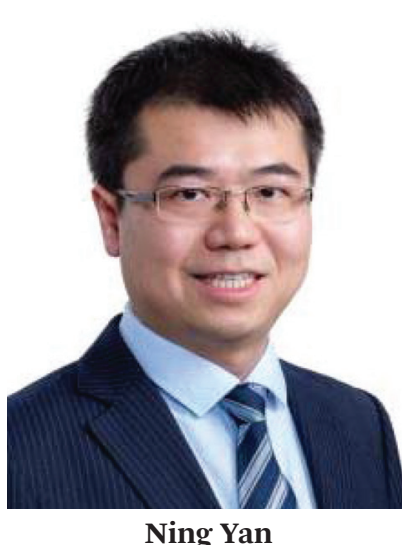

Ning Yan
Ning Yan received his B.Sc. and PhD degrees in Chemistry from Peking University working with Prof. Yuan Kou. After a Marie Curie Fellowship at the École Polytechnique Fédérale de Lausanne in Switzerland with Prof. Paul Dyson, he joined the Department of Chemical and Biomolecular Engineering at the National University of Singapore as an assistant professor in 2012 and was promoted to a tenured associate professor in 2018. Ning

Yan works actively in advanced catalysis, renewable energy, and sustainable chemistry. systems such as solid acids, ${ }^{8,14,25,31}$ metal catalysts, ${ }^{15}$ functionalised heterogeneous catalysts (e.g., carbon-based catalysts, metal-organic frameworks (MOFs), solid phase ionic liquid based catalysts, and magnetic iron oxide based catalysts). ${ }^{32}$ An updated and in-depth review on the theme of biomass valorisation over POM-based catalysts, to our knowledge, is not available. The aim of this review is to provide a detailed analysis integrating the state-of-the-art of the chemocatalytic conversion of biomass over POMs and metal-POM composites. While the focus is to show the wide applicability of POM-based catalysts in biorefinery, discussions on the relationship between the catalytic performance and the chemical/electronic/structural properties of the materials, as well as the reaction mechanisms, are also provided. For biomass valorisation over POMs, firstly the advances of acid catalysis including hydrolysis, dehydration, etherification, alcoholysis, transesterification and esterification are examined. Furthermore, applications in chemical oxidation for the synthesis of organic acids and furans are analysed. For biomass valorisation over metal-POM composites, an overview of tandem reactions (e.g. hydrolysis-hydrogenation, hydrolysis-oxidation, and hydrogenolysis-hydrodeoxygenation) is provided.

\section{Properties and preparation of POM-based catalysts}

Currently, most studies are focused on the Keggin and WellsDawson type of POM. The Keggin anion family is based on the $\left[\mathrm{XM}_{12} \mathrm{O}_{40}\right]^{n-}$ anion ( $\mathrm{X}=\mathrm{Si}, \mathrm{P}$, etc.; $\mathrm{M}=\mathrm{Mo}, \mathrm{W}$, etc.), while the Wells-Dawson anion family bears the chemical formula of $\left[\mathrm{X}_{2} \mathrm{M}_{18} \mathrm{O}_{62}\right]^{n-}$. ${ }^{4}$ POMs are versatile catalysts due to the multiple active sites, including protons as Brønsted acids, substituted metals with strong Lewis acidity, or metals with redox properties, and thus they are usually applied in acid-catalysed and oxidation reactions. ${ }^{3}$ POMs with protons as the only countercations are usually called heteropolyacids (HPAs). Phosphotungstic acid (PTA, $\mathrm{H}_{3} \mathrm{PW}_{12} \mathrm{O}_{40}, \mathrm{HPW}$ ), silicotungstic acid (STA, $\mathrm{H}_{4} \mathrm{SiW}_{12} \mathrm{O}_{40}, \mathrm{HSiW}$ ), phosphomolybdic acid (PMA, $\mathrm{H}_{3} \mathrm{PMO}_{12} \mathrm{O}_{40}$, HPMo) and silicomolybdic acid (SMA, $\mathrm{H}_{4} \mathrm{SiMo}_{12} \mathrm{O}_{40}$, HSiMo) with strong Brønsted acidity are widely applied in acid catalysis. As for oxidation catalysis, the reported POMs $\left[\mathrm{X}_{x} \mathrm{M}_{y} \mathrm{O}_{z}\right]^{n-}$ mainly contain $\mathrm{P}$ as the heteroelement X, and a combination of Mo and/or V as metal M. ${ }^{4,9,10}$

POMs are normally soluble in both water and polar organic solvents; thus inorganic cations $\left(\right.$ e.g. $\mathrm{Cs}^{+}, \mathrm{Ag}^{+}$, etc.) are usually employed as counter-cations to enhance the insolubility of POMs. In addition to inorganic cations, organic compounds with designable and flexible functional groups (e.g., organic amines, quaternary ammonium ions, organic surfactants, and ionic liquid cations) have also been adopted for the solidification of POMs. ${ }^{3,33}$ Meanwhile, various heterogeneous porous supports including transition metal oxides, clays, carbons, zeolites, mesoporous silicas, polymers, and MOFs, as well as magnetic nanoparticles (NPs) have been adopted for the immobilization of POMs. ${ }^{3,33}$ A variety of methods such as impreg- 
nation, co-precipitation, deposition precipitation, equilibrium adsorption and ion exchange have been developed..$^{3,5,12,33}$ Due to the increased thermal/hydrolytic/oxidative stability, these heterogeneous solidified/immobilised POMs have been widely applied as solid catalysts. ${ }^{3-5}$

Metal-POM composites, containing both the metal sites $(\mathrm{Ru}, \mathrm{Au}, \mathrm{Pd}, \mathrm{Pt}$, etc.) and POM sites, can be prepared by impregnation, encapsulation, physical mixing and other methods. ${ }^{3,15,16}$ These hybrid materials have also been applied in a variety of one-pot conversions of biomass feedstock in a tandem reaction sequence including the hydrolysis-hydrogenation, hydrolysis-oxidation, and hydrogenolysis-hydrodeoxygenation combinations, owing to the facilitated migration of the substrates/intermediates between the metal sites and POM sites. Since the preparation and characterization of POM-based catalysts have been covered in other excellent reviews, ${ }^{3,5,12,33}$ in this review, the emphasis is on the functionality of POM-based catalysts in biomass transformations.

\section{Biomass valorisation into renewable chemicals and fuels over POMs}

\subsection{Acid catalysis}

\subsubsection{Hydrolysis, dehydration and related reactions}

3.1.1.1 Monosaccharide and derivative synthesis. As the most abundant and valuable component of lignocellulosic biomass, cellulose is a linear biopolymer consisting of glucose units connected through $\beta$-1,4-glycosidic bonds. The hydrolysis of cellulose or raw lignocellulosic biomass by acid catalysts leads to the generation of oligosaccharides or monosaccharides such as glucose. ${ }^{7,8,26}$ Further dehydration results in the formation of hydroxymethylfurfural (HMF). ${ }^{21,22,34-37} \mathrm{HMF}$ has been widely accepted as an important platform chemical included in the "Top $10+4$ " list revised on the "Top 10" list described by the US Department of Energy (DOE). ${ }^{38}$ The "Top $10+4$ " list also includes other critical platform chemicals such as furfural (FAL), glycerol, levulinic acid (LA), lactic acid, sorbitol, which will be discussed in this review.

So far, multiple POM-based catalysts have been reported for glucose synthesis. ${ }^{78,26}$ The representative POMs for fructose production are summarised in Table 1. Mizuno et al. found that highly negatively charged HPAs (e.g., $\mathrm{H}_{5} \mathrm{BW}_{12} \mathrm{O}_{40}$, $\mathrm{H}_{5} \mathrm{AlW}_{12} \mathrm{O}_{40}$, and $\mathrm{H}_{5} \mathrm{GaW}_{12} \mathrm{O}_{40}$ ), in particular $\mathrm{H}_{5} \mathrm{BW}_{12} \mathrm{O}_{40}$, displayed higher activity than other typical HPAs (e.g., HPW and HSiW) for the saccharification of polysaccharides, due to the high acidity and hydrogen-bonding accepting ability to decrease the crystallinity of polysaccharides (Table 1 , entry 1). ${ }^{39}$ Wang et al. reported that a micellar HPA catalyst $\left[\mathrm{C}_{16} \mathrm{H}_{33} \mathrm{~N}\left(\mathrm{CH}_{3}\right)_{3}\right] \mathrm{H}_{2} \mathrm{PW}_{12} \mathrm{O}_{40}$ displayed a remarkable performance in the hydrolysis of polysaccharides (e.g., cellulose and starch), which is attributed to the facilitated access to catalytic sites by polysaccharide molecules, and the enhanced reaction rate and improved mass transport in the micellar catalyst

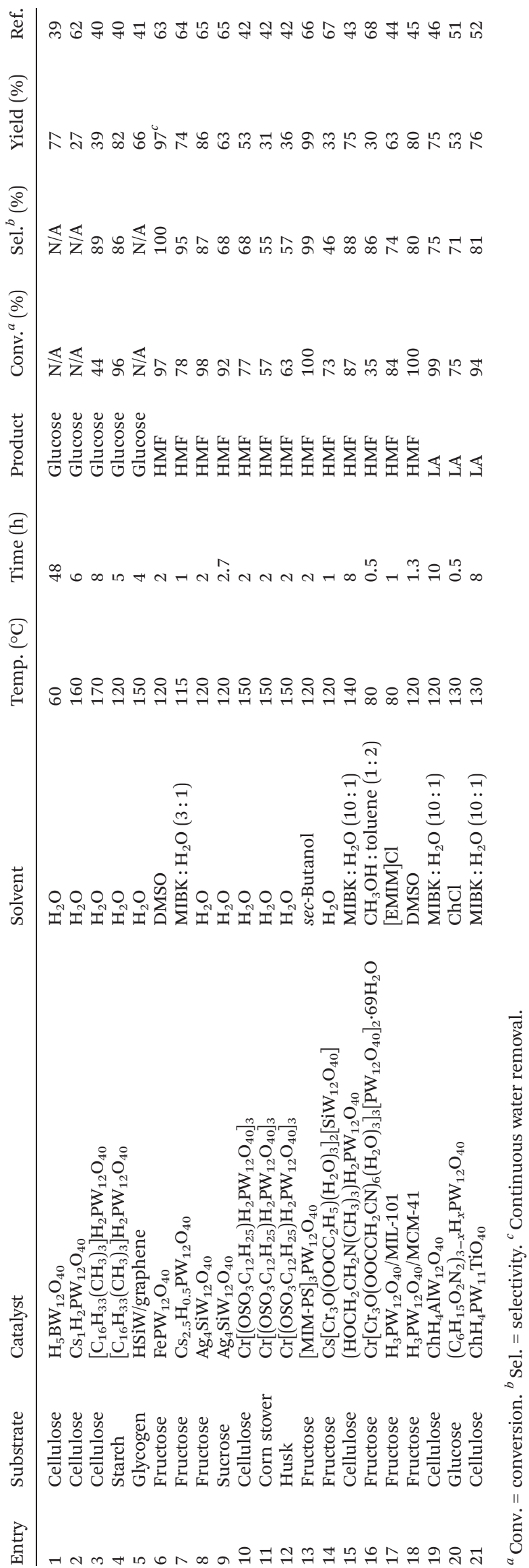


(Table 1, entries 3 and 4). ${ }^{40}$ Gedanken et al. prepared HSiW/ graphene via a sonochemical method for glucose synthesis from glycogen hydrolysis. The hydrophobic cavities on the graphene surface facilitated the anchoring of glycogen and promoted the attack of glycosidic bonds via protons, which resulted in selective and efficient hydrolysis (Table 1, entry 5). ${ }^{41}$

A variety of POMs have been evaluated for HMF generation..$^{21,22,34-37}$ In addition to monophasic systems such as water, organic solvents and ionic liquids, innovative biphasic aqueous/organic systems have also been employed, which efficiently remove the produced HMF from the reactive aqueous phase to the organic phase, thus minimising side reactions. $^{21,34,37}$ The representative POMs for the hydrolysis of polysaccharides/monosaccharides in monophasic and biphasic systems are summarised in Table 1. Wang and co-workers reported a micellar Brønsted-Lewis-surfactant-combined HPA catalyst $\mathrm{Cr}\left[(\mathrm{DS}) \mathrm{H}_{2} \mathrm{PW}_{12} \mathrm{O}_{40}\right]_{3}$ (DS represents dodecyl sulfate, $\mathrm{OSO}_{3} \mathrm{C}_{12} \mathrm{H}_{25}$ ) showing notable activity and stability for HMF synthesis from unpretreated lignocellulosic biomass (Table 1, entries 10-12). The enhanced performance is mainly attributed to the Brønsted and Lewis acidities, as well as the micellar structure with hydrophobic groups. ${ }^{42}$ The same authors prepared a series of $\left(\mathrm{HOCH}_{2} \mathrm{CH}_{2} \mathrm{~N}\left(\mathrm{CH}_{3}\right)_{3}\right)_{x} \mathrm{H}_{3-x} \mathrm{PW}_{12} \mathrm{O}_{40}$ $\left(\mathrm{Ch}_{x} \mathrm{H}_{3-x} \mathrm{PW}_{12} \mathrm{O}_{40}, x=1,2\right.$ and 3$)$ via choline chloride and HPW, and the highest HMF yield of $75 \%$ was achieved over $\mathrm{ChH}_{2} \mathrm{PW}_{12} \mathrm{O}_{40}$ after $8 \mathrm{~h}$ at $140{ }^{\circ} \mathrm{C}$ (Table 1, entry 15). ${ }^{43}$ The hydrophilic head of $\mathrm{Ch}_{x} \mathrm{H}_{3-x} \mathrm{PW}_{12} \mathrm{O}_{40}$ concentrates the cellulose substrate, while the hydrophobic tail inhibits further hydration of HMF to by-product LA, thus benefitting HMF production. POMs encapsulated in MOFs (e.g. MIL-101 ${ }^{44}$ ) or immobilised on porous supports (e.g. MCM-41 $1^{45}$ ) have also been adopted for HMF generation. For instance, Hensen et al. reported PTA/MIL-101-PTA encapsulated in MIL-101 as a composite catalyst to convert sugars. The system achieved the same $\mathrm{HMF}$ yield of $63 \%$ from fructose in [EMIM]Cl at $80^{\circ} \mathrm{C}$ after $1 \mathrm{~h}$ (Table 1 , entry 17 ), and in DMSO at $130{ }^{\circ} \mathrm{C}$ after $30 \mathrm{~min}^{44}$

Furthermore, various POMs have been evaluated for the production of LA or levulinate ester from carbohydrates in consecutive reactions. ${ }^{46-61}$ Novel temperature-responsive HPA nanohybrids $\left[\left(\mathrm{CH}_{3}\right)_{3} \mathrm{NCH}_{2} \mathrm{CH}_{2} \mathrm{OH}\right]_{n} \mathrm{H}_{5-n} \mathrm{AlW}_{12} \mathrm{O}_{40}$ $\left(\mathrm{Ch}_{n} \mathrm{H}_{5-n} \mathrm{AlW}_{12} \mathrm{O}_{40}\right)^{46}$ and $\mathrm{ChH}_{4} \mathrm{PW}_{11} \mathrm{TiO}_{40}{ }^{52}$ HPA-based ionic liquid catalysts including $[\mathrm{PyPS}]_{3} \mathrm{PW}_{12} \mathrm{O}_{40}$ [PyPS = 1-(3-sulfopropyl)pyridinium $]^{47}$ and $\left[\mathrm{C}_{4} \mathrm{H}_{6} \mathrm{~N}_{2}\left(\mathrm{CH}_{2}\right)_{3} \mathrm{SO}_{3} \mathrm{H}\right]_{3-n} \mathrm{H}_{n} \mathrm{PW}_{12} \mathrm{O}_{40},{ }^{55}$ HPAs with Brønsted and Lewis acidic sites $\mathrm{H}_{n} \mathrm{PW}_{11} \mathrm{MO}_{39}(\mathrm{M}=$ $\mathrm{Cu}^{\mathrm{II}}, \mathrm{Zn}^{\mathrm{II}}, \mathrm{Cr}^{\mathrm{III}}, \mathrm{Fe}^{\mathrm{II}} \mathrm{I}, \mathrm{Sn}^{\mathrm{IV}}, \mathrm{Ti}^{\mathrm{IV}}$, and $\mathrm{Zr}^{\mathrm{IV}}$; for $\mathrm{Ti}$ and $\left.\mathrm{Zr}\right),{ }^{48,49,52}$, combination of Zr-MCM-41 and HPW catalysts with tuneable Lewis and Brønsted acidity, ${ }^{50}$ as well as acid-base bifunctional HPA nanospheres $\left(\mathrm{C}_{6} \mathrm{H}_{15} \mathrm{O}_{2} \mathrm{~N}_{2}\right)_{3-x} \mathrm{H}_{x} \mathrm{PW}_{12} \mathrm{O}_{40}{ }^{51}$ were developed. Different reaction media including supercritical methanol, water-methanol mixtures, ${ }^{53}$ and water-methyl isobutyl ketone $(\mathrm{MIBK})^{52,55}$ were also explored. For example, Wang and co-workers developed novel temperature-responsive $\mathrm{Ch}_{n} \mathrm{H}_{5-n} \mathrm{AlW}_{12} \mathrm{O}_{40}$ catalysts, which dissolve at high temperature and precipitate from the reaction medium at room tempera-

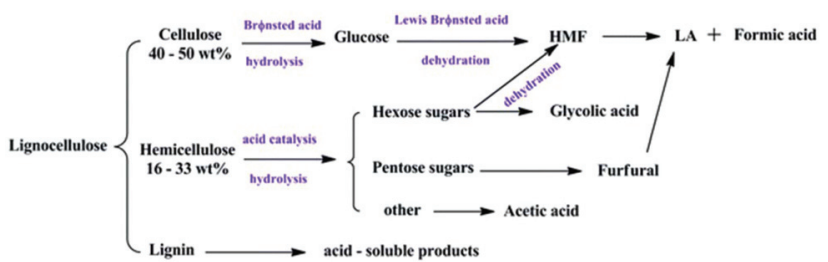

Fig. 1 Conversion pathways of cellulose into levulinic acid. ${ }^{46}$ Reproduced from ref. 46 with permission from The Royal Society of Chemistry, copyright 2016.

ture. Among the tested catalysts, $\mathrm{ChH}_{4} \mathrm{AlW}_{12} \mathrm{O}_{40}$ exhibited the highest LA yield of $74.8 \%$ with a cellulose conversion of $98.9 \%$ in one pot, due to the synergistic effects of the temperaturestimulus, and dual Lewis and Brønsted acidity (Table 1, entry 19). ${ }^{46}$ As shown in Fig. 1, the Brønsted acid sites are proposed to facilitate hydrolysis, isomerization and dehydration/rehydration pathways, while Lewis acid sites are beneficial for isomerization of glucose to fructose.

3.1.1.2 Acrolein synthesis. The significant surge in biodiesel production via transesterification of triglycerides with methanol is accompanied by a substantial increase of glycerol generation as a by-product (ca. $10 \mathrm{wt} \%$ ). Acrolein synthesis via the dehydration of glycerol is a promising method for glycerol valorisation, as acrolein is an important intermediate for valued-added chemicals such as acrylic acid and amino-acid DL-methionine. ${ }^{23,69-72}$ POMs supported on oxides (e.g. titania, ${ }^{73}$ niobia, ${ }^{74,75}$ alumina, ${ }^{76,77}$ silica, alumosilicate, ${ }^{78}$ and zirconium dioxide ${ }^{77,79}$ ) and molecular sieves (MCM-41, ${ }^{80}$ amino siloxane-functionalised MCM- $41,{ }^{80,81} \mathrm{Zr}-\mathrm{MCM}-41,{ }^{82,83}$ SBA- $15,{ }^{84}$ and $\mathrm{ZSM}-5^{85}$ ) have been reported for acrolein synthesis from glycerol. For example, Yun et al. prepared the Keggin type $\mathrm{H}_{3} \mathrm{PW}_{12} \mathrm{O}_{40} / \mathrm{MCM}-41$ and Wells-Dawson type $\mathrm{H}_{6} \mathrm{P}_{2} \mathrm{~W}_{18} \mathrm{O}_{62} / \mathrm{MCM}-41$ for the dehydration of glycerol to acrolein. The selectivity to acrolein increased with the increasing ratio of Brønsted to Lewis acids, while the lower ratio of Brønsted/Lewis acids favoured the production of hydroxyacetone as undesired side products. ${ }^{80}$

\subsubsection{Etherification and alcoholysis. 5-} Ethoxymethylfurfural (EMF) is a potential biofuel alternative due to its high energy density $\left(30.3 \mathrm{MJ} \mathrm{L}^{-1}\right)$ similar to gasoline (31.9 $\mathrm{MJ} \mathrm{L}^{-1}$ ) and diesel (33.6 $\mathrm{MJ} \mathrm{L}^{-1}$ ), as well as lower emission of soot, $\mathrm{NO}_{x}$ and $\mathrm{SO}_{x}$. Thus, EMF production from HMF or monosaccharides has attracted much attention. ${ }^{86}$ The representative POM catalysts for EMF synthesis via etherification, and dehydrative etherification in monophasic and biphasic systems are summarised in Table 2. Chen et al. prepared MOFbased POMs [Cu-BTC][HPM] (NENU-5) (BTC = benzene-1,3,5tricarboxylate, HPM = phosphomolybdic acid hydrate) for the conversion of HMF to EMF and ethyl levulinate (Fig. 2). ${ }^{87}[\mathrm{Cu}-$ BTC][HPM] consisted of guest molecules of HPM in the pores of the insoluble Cu-BTC host and displayed remarkable catalytic activity and stability. Maximum EMF and ethyl levulinate (EL) yields of $68.4 \%$ and $20.2 \%$ were obtained at $140{ }^{\circ} \mathrm{C}$ after $12 \mathrm{~h}$, respectively (Table 2 ). 
Table 2 Etherification and dehydrative etherification for 5-ethoxymethylfurfural synthesis over POM catalysts

\begin{tabular}{|c|c|c|c|c|c|c|c|c|}
\hline Substrate & Catalyst & Solvent & Temp. ${ }^{a}\left({ }^{\circ} \mathrm{C}\right)$ & Time (h) & Conv. $^{b}(\%)$ & $\operatorname{Sel}^{c}(\%)$ & Yield (\%) & Ref. \\
\hline HMF & $\mathrm{H}_{4} \mathrm{SiW}_{12} \mathrm{O}_{40} / \mathrm{MCM}-41$ & Ethanol & 90 & 2 & 92 & 84 & 81 & 88 \\
\hline $\mathrm{HMF}$ & {$[\mathrm{MIMBS}]_{3} \mathrm{PW}_{12} \mathrm{O}_{40}$} & Ethanol & 70 & 24 & 98 & 93 & 91 & 89 \\
\hline $\mathrm{HMF}$ & $\mathrm{Fe}_{3} \mathrm{O}_{4} @ \mathrm{SiO}_{2}-\mathrm{HPW}$ & Ethanol & 100 & 11 & 98 & 86 & 84 & 90 \\
\hline HMF & K-10 clay-HPW & Ethanol & 100 & 10 & 98 & 93 & 92 & 91 \\
\hline HMF & [Cu-BTC $][\mathrm{HPM}](\mathrm{NENU}-5)$ & Ethanol & 140 & 12 & N/A & N/A & 68 & 87 \\
\hline Fructose & $\mathrm{H}_{3} \mathrm{PW}_{12} \mathrm{O}_{40}$ & Ethanol : THF(5:3) & 130 & 0.5 & 98 & 77 & 76 & 92 \\
\hline Fructose & {$[\mathrm{MIMBS}]_{3} \mathrm{PW}_{12} \mathrm{O}_{40}$} & Ethanol & 90 & 24 & N/A & N/A & 91 & 89 \\
\hline Fructose & $\mathrm{Fe}_{3} \mathrm{O}_{4} @ \mathrm{SiO}_{2}-\mathrm{HPW}$ & Ethanol & 100 & 24 & N/A & N/A & 55 & 90 \\
\hline Fructose & K-10 clay-HPW & Ethanol & 100 & 24 & 100 & 62 & 62 & 91 \\
\hline Fructose & $\mathrm{H}_{3} \mathrm{PW}_{12} \mathrm{O}_{40}$ & Ethanol : DMSO(7:3) & 140 & 2 & 99 & 64 & 64 & 93 \\
\hline
\end{tabular}

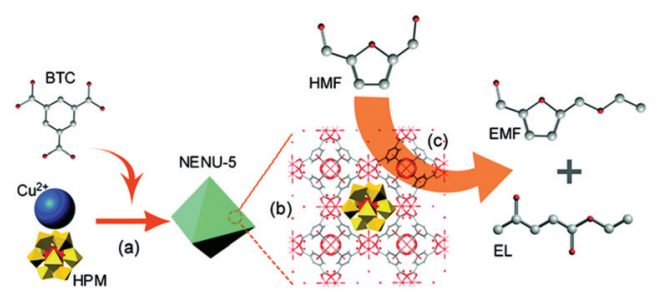

Fig. 2 Schematic illustration of the synthesis and catalysis procedure. (a) Synthesis of the catalyst. (b) The crystal structure of the catalyst. (c) The procedure of conversion of HMF into EMF and EL. ${ }^{87}$ Reproduced from ref. 87 with permission from The Royal Society of Chemistry, copyright 2016.

3.1.3 Esterification and transesterification: biodiesel and additive synthesis

3.1.3.1 Biodiesel synthesis. Biodiesel is a non-toxic, biodegradable, environmentally friendly fuel alternative or additive of the petroleum-derived diesel. As a mixture of $\mathrm{C}_{12}-\mathrm{C}_{22}$ fatty acid monoalkyl esters (FAMEs), biodiesel is obtained by transesterification of the triacylglyceride (TAG) component and/or esterification of free fatty acids (FFAs) with $\mathrm{C}_{1}-\mathrm{C}_{2}$ alcohols in plant oils, animal fat or algae (Fig. 3). ${ }^{12-14,35,94}$ In contrast to "first-generation" biodiesel derived from edible feedstock (e.g., soybean oil), increasing research interest is focused on the "second-generation" biodiesel from inedible feedstock (e.g. jatropha oil and horn oil) or waste cooking/frying oils. ${ }^{13,35}$ The fatty acid chain is mainly classified into saturated and

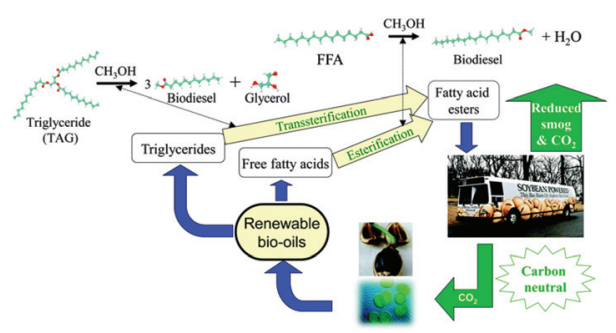

Fig. 3 Biodiesel production from renewable bio-oils via transesterification and esterification. ${ }^{13}$ Reproduced from ref. 13 with permission from The Royal Society of Chemistry, copyright 2014. unsaturated chains with chain lengths of 16 and 18 carbons, including stearic, oleic, linolenic and palmitic acids. ${ }^{12}$ For biodiesel production, parameters such as acid strength, structural porosity and surface hydrophobicity exert substantial impact on the catalytic performance. ${ }^{12,14}$ The representative inorganic cation/organo-solidified POMs and POMs supported on metal oxides, clays, zeolites, mesoporous silica, magnetic materials, and MOFs for biodiesel production are summarised in Table 3.

Guo and co-workers prepared novel organic-inorganic hybrid catalysts, HPA and $\mathrm{ZrO}_{2}$ bifunctionalised organosilica hollow nanospheres $\left(\mathrm{H}_{3} \mathrm{PW}_{12} \mathrm{O}_{40} / \mathrm{ZrO}_{2}\right.$-Et-HNS). ${ }^{95} \mathrm{H}_{3} \mathrm{PW}_{12} \mathrm{O}_{40} /$ $\mathrm{ZrO}_{2}$-Et-HNS: due to the strong Brønsted and Lewis acidity, unique hollow nanospherical morphology and hydrophobic surface, this material displayed encouraging activity and recyclability for transesterification of yellow horn oil with methanol to biodiesel, as well as esterification of levulinic acid (LA) with methanol to methyl levulinate (discussed in 3.1.3.2). The hollow nanospherical morphology enhanced the accessibility of guest molecules to the acid sites, shortened the diffusion pathway and enhanced the diffusion efficiency. The hydrophobic surface of the hybrid catalysts induced by the incorporation of bridging ethyl groups facilitated the enrichment of the hydrophobic reactant and expulsion of the hydrophilic products, thus accelerating the reaction (Fig. 4).

Li et al. prepared core-shell structured HPW-PGMA-MNPs composed of iron oxide magnetic NPs (MNP) as the core, poly (glycidyl methacrylate) (PGMA) as the shell, and HPW as the surface acid group. HPW-PGMA-MNPs exhibited remarkable activity and good recyclability for the one-pot transformation of waste grease to biodiesel via simultaneous esterification of FFAs and transesterification of TAG with methanol, as a result of the firm attachment of HPW on MNPs via covalent binding, the stable PGMA shell, and the superparamagnetic properties of the MNPs (Fig. 5). ${ }^{96}$

Shul et al. prepared bifunctional core-shell HPA-functionalised zeolitic imidazolate framework-8 (ZIF-8) NPs via imidazolium medium. The strong $\mathrm{O}-\mathrm{N}$ bonding indicated the strong interaction between the Keggin structure in HPA and imidazole units in ZIF-8 NPs. The optimised ZIF-8/HPA with both acidic and basic sites, and large surface areas displayed 
Table 3 Biodiesel production over inorganic cation/organo-solidified POMs and POMs supported on metal oxides, clays, zeolites, mesoporous silica, magnetic materials, and MOFs

\begin{tabular}{|c|c|c|c|c|c|c|c|c|}
\hline Support & Catalyst & Feedstock & Cat. (wt\%) & $\begin{array}{l}\text { Alcohol/ } \\
\text { feedstock } \\
\text { mole ratio }\end{array}$ & $\begin{array}{l}\text { Temp. }{ }^{a} \\
\left({ }^{\circ} \mathrm{C}\right)\end{array}$ & $\begin{array}{l}\text { Time } \\
\text { (h) }\end{array}$ & $\begin{array}{l}\text { Conv. }^{b} / \\
\text { yield }^{c} \\
(\%)\end{array}$ & Ref. \\
\hline \multirow[t]{3}{*}{ Inorganic cation } & $\mathrm{Zn}_{1.2} \mathrm{H}_{0.6} \mathrm{PW}_{12} \mathrm{O}_{40}$ & Waste cooking oil & 2.5 & 28 & 65 & 12 & $97^{b}$ & 98 \\
\hline & $\mathrm{Cs}_{2.5} \mathrm{H}_{0.5} \mathrm{PW}_{12} \mathrm{O}_{40}$ & Yellow horn oil ${ }^{e}$ & 1 & 12 & 60 & 0.2 & $96^{c}$ & 99 \\
\hline & $\mathrm{Cs}_{1.5} \mathrm{H}_{1.5} \mathrm{PW}_{12} \mathrm{O}_{40}$ & Jatropha oil & 3 & 25 & 65 & 0.6 & $91^{c}$ & 100 \\
\hline \multirow[t]{2}{*}{ Organo-solidified } & $\left(\mathrm{C}_{6} \mathrm{H}_{15} \mathrm{O}_{2} \mathrm{~N}_{2}\right)_{2} \mathrm{HPW}_{12} \mathrm{O}_{40}$ & Eruca sativa gars (ESG) oil & 9 & 9 & 65 & 12 & $91^{b}$ & 101 \\
\hline & $\left(\mathrm{NH}_{2} \mathrm{CH}_{2} \mathrm{COOH}\right) \mathrm{H}_{2} \mathrm{PW}_{12} \mathrm{O}_{40}$ & Palmitic acid & 6 & 12 & 90 & 3 & $93^{c}$ & 102 \\
\hline Ionic liquid & {$[\mathrm{MIM}-\mathrm{PSH}] \mathrm{H}_{2} \mathrm{PW}_{12} \mathrm{O}_{40}$} & Palmitic acid & 7 & 13 & 80 & 5 & $92^{c}$ & 103 \\
\hline \multirow[t]{7}{*}{ Oxide } & $\mathrm{Ta}_{2} \mathrm{O}_{5} / \mathrm{SiO}_{2}-\left[\mathrm{H}_{3} \mathrm{PW}_{12} \mathrm{O}_{40} / \mathrm{R}\right](\mathrm{R}=\mathrm{Me}$ or $\mathrm{Ph})$ & Soybean oil (20\% myristic acid) & 2 & 90 & 65 & 24 & $90^{c}$ & 104-106 \\
\hline & $20 \% \mathrm{H}_{3} \mathrm{PW}_{12} \mathrm{O}_{40} / \mathrm{ZrO}_{2}$ & Oleic acid & 10 & 6 & 100 & 4 & $88^{b}$ & 107 \\
\hline & $25 \% \mathrm{H}_{3} \mathrm{PW}_{12} \mathrm{O}_{40} / \mathrm{Nb}_{2} \mathrm{O}_{5}$ & Used cooking oil & 3 & 18 & 200 & 20 & $92^{c}$ & 108 \\
\hline & $15 \% \mathrm{TPA} / \mathrm{SnO}_{2}$ & Palmitic acid & 1 & 14 & 65 & 4 & $81^{b}$ & 109 \\
\hline & $25 \%$ TPA- $\mathrm{Al}_{2} \mathrm{O}_{3}$ & Jatropha oil $^{d}$ & 4 & 19 & 65 & 0.8 & $84^{c}$ & 110 \\
\hline & $\mathrm{H}_{3} \mathrm{PW}_{12} \mathrm{O}_{40}-\mathrm{ZrO}_{2}-\mathrm{Si}(\mathrm{Et}) \mathrm{Si}-60$ & Eruca sativa gars oil & 5 & 90 & 65 & 24 & $75-99^{c}$ & 111 \\
\hline & $\mathrm{H}_{3} \mathrm{PW}_{12} \mathrm{O}_{40} / \mathrm{ZrO}_{2}$-Et-HNS-2.0 & Yellow horn oil & 5 & 90 & 65 & 24 & $63-76^{c}$ & 95 \\
\hline \multirow[t]{2}{*}{ Clay } & $20 \% \mathrm{HPW} /$ metakaolin flint & Oleic acid & 5 & 30 & 130 & 2 & $97^{c}$ & 112 \\
\hline & $20 \% \mathrm{H}_{3} \mathrm{PW}_{12} \mathrm{O}_{40} / \mathrm{K} 10$ & Oleic acid & 5 & 8 & 165 & 5 & $100^{b}$ & 113 \\
\hline \multirow[t]{2}{*}{ Carbon } & $\mathrm{H}_{3} \mathrm{PW}_{12} \mathrm{O}_{40} / \mathrm{ACF}$ & Palmitic acid & 1.4 & 97 & 60 & 6 & $88^{b}$ & 114 \\
\hline & $20 \%$ TPA-AC & Jatropha oil $^{d}$ & 4 & 20 & 65 & 0.66 & $87^{c}$ & 115 \\
\hline \multirow[t]{2}{*}{ Zeolite } & $30 \% \mathrm{H}_{3} \mathrm{PW}_{12} \mathrm{O}_{40} / \mathrm{H} \beta$ & Oleic acid & 0.1 & 20 & 60 & 6 & $84^{b}$ & 116 \\
\hline & $30 \% \mathrm{SiW}_{12} / \mathrm{H} \beta$ & Oleic acid & 0.1 & 20 & 60 & 10 & $86^{b}$ & 117 \\
\hline \multirow[t]{6}{*}{ Mesoporous silica } & $23 \% \mathrm{H}_{3} \mathrm{PW}_{12} \mathrm{O}_{40} / \mathrm{SBA}-15$ & Oleic acid & 0.3 & 40 & 40 & 4 & $90^{b}$ & 118 \\
\hline & $\mathrm{TSA}_{3} / \mathrm{SBA}-15$ & Waste cooking oil & 0.3 & 8 & 65 & 8 & $86^{b}$ & 119 \\
\hline & 45\%TPA/SBA- 15 & Canola oil & 3 & 26 & 200 & 6 & $97^{c}$ & 120 \\
\hline & $\mathrm{TPA}_{3} / \mathrm{MCM}-41$ & Palmitic acid & 0.1 & 40 & 60 & 6 & $100^{b}$ & 121 \\
\hline & $30 \% \mathrm{H}_{3} \mathrm{PW}_{12} \mathrm{O}_{40} / \mathrm{MCM}-41$ & Lauric acid & & 2 & 90 & 3 & $95^{c}$ & 122 \\
\hline & $30 \% \mathrm{SiW}_{11} / \mathrm{MCM}-41$ & Oleic acid & 0.1 & 40 & 65 & 16 & $81^{b}$ & 123 \\
\hline Magnetic NPs & HPW-PGMA-MNPS & Grease & 4 & 33 & 122 & 24 & $98^{c}$ & 96 \\
\hline \multirow[t]{2}{*}{ MOF } & ZIF-8/HPA & Rapeseed oil & 4 & 10 & 200 & 2 & $98^{b}$ & 97 \\
\hline & AILs/HPW/UiO-66-2COOH & Soybean oil & 10 & 35 & 110 & 6 & $96^{b}$ & 124 \\
\hline
\end{tabular}

${ }^{a}$ Temp. $=$ temperature.${ }^{b}$ Conv. $=$ conversion. ${ }^{c}$ Yield. ${ }^{d}$ Assisted by ultrasonic energy ${ }^{e}$ Microwave.

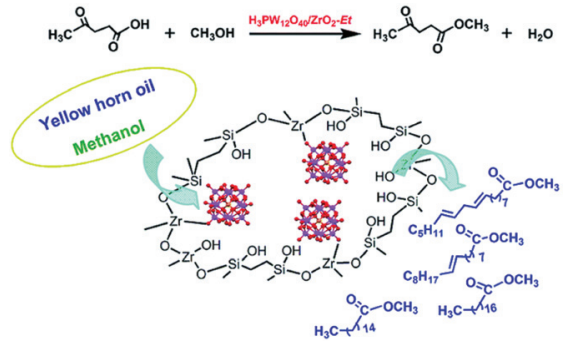

Fig. 4 The shell composition of $\mathrm{H}_{3} \mathrm{PW}_{12} \mathrm{O}_{40} / \mathrm{ZrO}_{2}$-Et hollow nanospheres and the processes of levulinic acid esterification and yellow horn oil transesterification catalysed over $\mathrm{H}_{3} \mathrm{PW}_{12} \mathrm{O}_{40} / \mathrm{ZrO}_{2}$-Et hollow nanosphere hybrid catalysts. ${ }^{95}$ Reproduced from ref. 95 with permission from The Royal Society of Chemistry, copyright 2014.

notable activity and recyclability for the transesterification of rapeseed oil with methanol to biodiesel (Fig. 6). ${ }^{97}$

3.1.3.2 Synthesis of levulinate esters. Levulinate esters have potential applications in the fragrance and flavouring industry, as blending agents in biodiesel, etc. In particular, ethyl levulinate (EL) is a novel diesel miscible biofuel. Levulinate esters are generally obtained via esterification of levulinic acid (LA), one of the most important platform molecules in the "Top 10 +4 " list mentioned earlier. The typical POM-based catalysts for

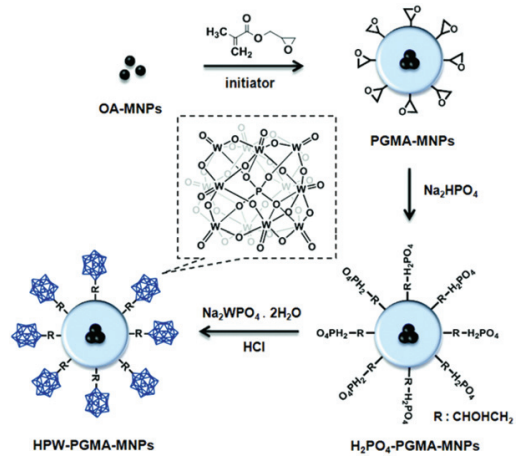

Fig. 5 Synthesis of phosphotungstic acid-functionalised iron oxide particles (HPW-PGMA-MNPs) as a magnetic nano-size solid acid catalyst. ${ }^{96}$ Reproduced from ref. 96 with permission from The Royal Society of Chemistry, copyright 2014

esterification of levulinic acid to alkyl levulinate are summarised in Table 4.

Guo and co-workers prepared $\mathrm{ZrO}_{2}$-based organic-inorganic hybrid catalysts functionalised by Keggin-type HPA and hydrophobic alkyl groups (i.e., benzene-terminally bonded and ethane-/benzene-bridged organosilica moieties), $\mathrm{H}_{3} \mathrm{PW}_{12} \mathrm{O}_{40} /$ $\mathrm{ZrO}_{2}-\mathrm{Si}(\mathrm{Et} / \mathrm{Ph}) \mathrm{Si}$ and $\mathrm{H}_{3} \mathrm{PW}_{12} \mathrm{O}_{40} / \mathrm{ZrO}_{2}-\mathrm{Si}(\mathrm{Ph}) .{ }^{125} \mathrm{H}_{3} \mathrm{PW}_{12} \mathrm{O}_{40} /$ 


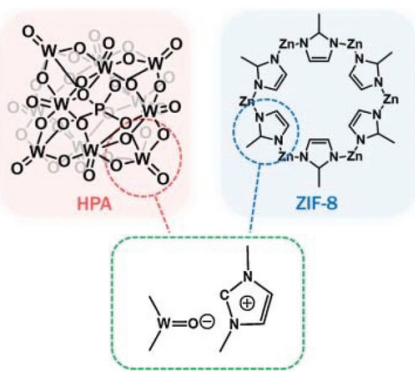

Fig. 6 Illustration of the plausible chemical bonding structure for the hybrid ZIF-8/HPA bifunctional catalyst for the transesterification of rapeseed oil. ${ }^{97}$ Reproduced from ref. 97 with permission from Elsevier, copyright 2019.

$\mathrm{ZrO}_{2}$-Si(Et/Ph)Si and $\mathrm{H}_{3} \mathrm{PW}_{12} \mathrm{O}_{40} / \mathrm{ZrO}_{2}-\mathrm{Si}(\mathrm{Ph})$ exhibited excellent catalytic activity and stability for the esterification of LA. The authors attributed the superior catalytic performance to the strong Brønsted and Lewis acidity, unique textural properties and the hydrophobic surface that inhibit the strong adsorption of the hydrophilic by-products. In particular, the ordered 2D hexagonal mesostructured $\mathrm{H}_{3} \mathrm{PW}_{12} \mathrm{O}_{40} / \mathrm{ZrO}_{2}-\mathrm{Si}(\mathrm{Ph})$ Si exhibited higher activity than $3 \mathrm{D}$ wormhole-like $\mathrm{H}_{3} \mathrm{PW}_{12} \mathrm{O}_{40} /$ $\mathrm{ZrO}_{2}$-Si(Et)Si and $\mathrm{H}_{3} \mathrm{PW}_{12} \mathrm{O}_{40} / \mathrm{ZrO}_{2}-\mathrm{Si}(\mathrm{Ph})$, due to the higher diffusion efficiency in the ordered mesoporous structure (Fig. 7). The same authors developed HPA and $\mathrm{ZrO}_{2}$ bifunctionalised organosilica nanohybrids $\mathrm{PW}_{12} / \mathrm{ZrO}_{2}-\mathrm{Si}(\mathrm{Et}) \mathrm{Si}$ with a $1 \mathrm{D}$ hollow tubular nanostructure, a 2D hexagonal periodic mesostructure and a 3D interconnected mesostructure. ${ }^{126}$ Among these, HPW and $\mathrm{ZrO}_{2}$-bifunctionalised organosilica nanotubes $\mathrm{PW}_{12} / \mathrm{ZrO}_{2}$-Si(Et)Si-NTs exhibited the highest activity for alkyl levulinates by LA esterification (Fig. 8).

\subsection{Oxidation}

The carbohydrate feedstock has high oxygen content; thus oxidation into oxygen-containing chemicals or oxygen removal via dehydration, hydrogenolysis, or hydrodeoxygenation is a convenient pathway. The catalytic oxidation of carbohydrates and their derivatives provide a variety of value-added fine chemicals, including organic acids (e.g. formic acid, glycolic acid, gluconic acid, lactic acid, and acrylic acid), ${ }^{4,10,11}$ as well as furan chemicals (e.g. 2,5-diformylfuran)., ${ }^{9,131}$

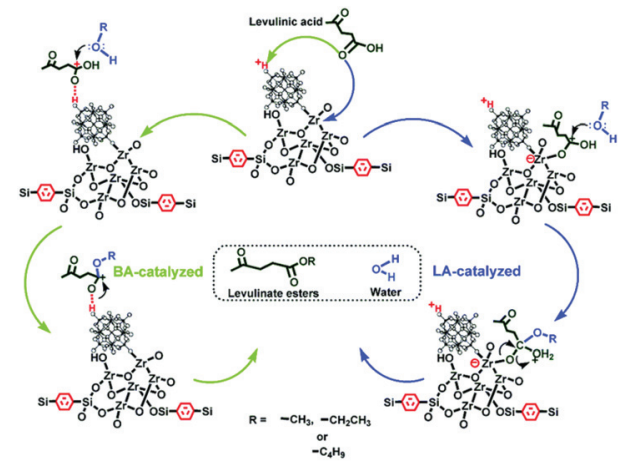

Fig. 7 The process of esterification of LA with alcohol to produce levulinate ester over $\mathrm{H}_{3} \mathrm{PW}_{12} \mathrm{O}_{40} / \mathrm{ZrO}_{2}-\mathrm{Si}(\mathrm{Ph}) \mathrm{Si}$ hybrid materials. Left part: Brønsted acid site-catalysed reaction; right part: Lewis acid site-catalysed reaction. ${ }^{125}$ Reproduced from ref. 125 with permission from The Royal Society of Chemistry, copyright 2013.

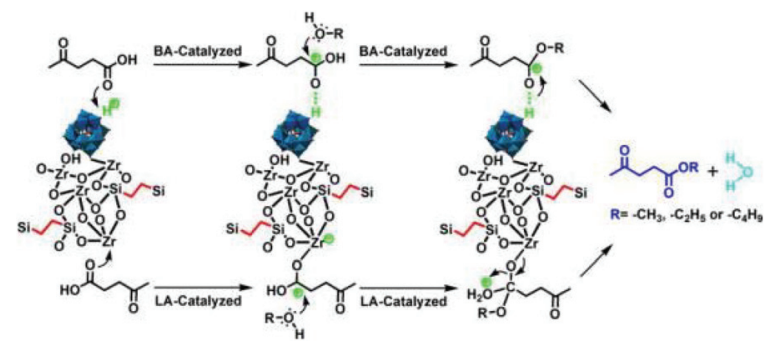

Fig. 8 Possible reaction mechanism of the synthesis of alkyl levulinates from the esterification of levulinic acid over $\mathrm{PW}_{12} / \mathrm{ZrO}_{2}-\mathrm{Si}(\mathrm{Et}) \mathrm{Si}-\mathrm{NT}$ nanohybrids. ${ }^{126}$ Reproduced from ref. 126 with permission from Elsevier, copyright 2016.

\subsubsection{Organic acid synthesis}

3.2.1.1 Oxidation of carbohydrates to formic acid. Formic acid (FA) is a versatile chemical finding widespread applications. It is used as a $\mathrm{H}_{2}$ donor in hydrogenation reactions, as well as a hydrogen storage compound in the context of hydrogen economy. Research studies have been focused on sustainable FA generation from oxidation of monosaccharides, oligosaccharides, and bio-polymers such as cellulose, hemicellulose, lignin and even algae, under mild conditions with

Table 4 Esterification of levulinic acid to alkyl levulinate over POM-based catalysts

\begin{tabular}{|c|c|c|c|}
\hline Catalysts & Reaction conditions $^{a}$ & Conv. ${ }^{b} /$ yield (\%) & Ref. \\
\hline $\mathrm{H}_{4} \mathrm{SiW}_{12} \mathrm{O}_{40}-\mathrm{SiO}_{2}$ & $0.1 \mathrm{~g} / 50 / 65 / 6$ & 73 & 128 \\
\hline $\mathrm{H}_{3} \mathrm{PW}_{12} \mathrm{O}_{40} / \mathrm{ZrO}_{2}-\mathrm{Si}(\mathrm{Ph}) \mathrm{Si}-1.0$ & $2 \mathrm{wt} \% / 7 / 65 / 3$ & 99.9 & 125 \\
\hline $\mathrm{H}_{3} \mathrm{PW}_{12} \mathrm{O}_{40} / \mathrm{ZrO}_{2}-\mathrm{Si}(\mathrm{Et}) \mathrm{Si}-1.0$ & & 68 & \\
\hline $\mathrm{H}_{3} \mathrm{PW}_{12} \mathrm{O}_{40} / \mathrm{ZrO}_{2}-\mathrm{Si}(\mathrm{Ph})-1.0$ & & 72 & \\
\hline $\mathrm{H}_{3} \mathrm{PW}_{12} \mathrm{O}_{40} / \mathrm{ZrO}_{2}$-Et-HNS-2.0 & $2 \mathrm{wt} \% / 7 / 65 / 1$ & 92 & 95 \\
\hline
\end{tabular}

${ }^{a}$ Reaction conditions: Amount of catalyst wt $\% /$ molar ratio of alcohol to substrate/reaction temperature in ${ }^{\circ} \mathrm{C} /$ reaction time in $\mathrm{h} .{ }^{b}$ Conv. $=$ conversion. 


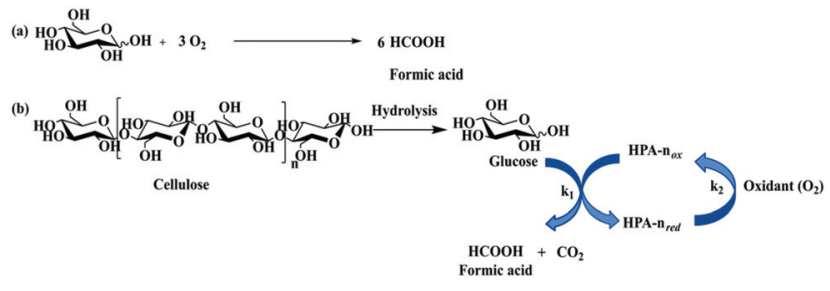

Fig. 9 (a) Overall stoichiometric reaction for oxidation of glucose into formic acid; (b) oxidative conversion of carbohydrates (e.g. cellulose) to formic acid over $\mathrm{H}_{3+n} \mathrm{PV}_{n} \mathrm{Mo}_{12-n} \mathrm{O}_{40}$ (HPA) catalysts. HPA- $n_{\text {ox }}$ : The oxidised state of HPA and HPA- $n_{\text {red: }}$ the reduced state of HPA. ${ }^{9}$ Reproduced from ref. 9 with permission from The Royal Society of Chemistry, copyright 2018

molecular oxygen or air as an oxidant..$^{9-11,132,133}$ The oxidative conversion of cellulose includes the hydrolysis of highly polymerised cellulose into glucose over acid sites and the subsequent oxidative $\mathrm{C}-\mathrm{C}$ bond cleavage of glucose into $\mathrm{FA}$ over redox sites, while overoxidation leads to the formation of $\mathrm{CO}_{2}$ which is the thermodynamically favoured product. Keggin-type phosphovanadomolybdates, $\mathrm{H}_{3+n} \mathrm{PV}_{n} \mathrm{Mo}_{12-n} \mathrm{O}_{40}$ (HPA- $n$ ), with $n=0-6$, are typical catalysts for the oxidative conversion of biomass to FA (Fig. 9). The representative $\mathrm{H}_{3+n} \mathrm{PV}_{n} \mathrm{Mo}_{12-n} \mathrm{O}_{40}$ (HPA- $n$ ) catalysts for the oxidation of carbohydrates to formic acid are summarised in Table 5 .
Wasserscheid et al. firstly reported the oxidation of carbohydrate-based biomass to FA over $\mathrm{H}_{5} \mathrm{PV}_{2} \mathrm{Mo}_{10} \mathrm{O}_{40} \cdot{ }^{134}$ An FA yield of around $50 \%$ with nearly full conversion was obtained from monosaccharides (glucose and xylose) and disaccharides (cellobiose and sucrose) at $80{ }^{\circ} \mathrm{C}$ and $3 \mathrm{MPa} \mathrm{O}_{2}$ after $26 \mathrm{~h}$ (Table 5, entry 1). However, water-insoluble cellulose only offered an FA yield of $1 \%$ under the same reaction conditions. Wasserscheid et al. further investigated the activity of $\mathrm{H}_{3+n} \mathrm{PV}_{n} \mathrm{Mo}_{12-n} \mathrm{O}_{40}(n=0-6)$ in selective oxidation of biomass to FA, and found that a higher degree of V-substitution enhanced the catalytic activity. The highest activity was obtained over HPA-5 (Table 5, entry 3), ${ }^{135}$ probably due to the formation of pervanadyl $\left(\mathrm{VO}^{2+}\right)$ cations that are known to be a strong oxidative species.

The addition of inorganic or organic acids can further increase the FA yield due to the facilitated hydrolysis of cellulose. Fu et al. reported an FA yield of $34 \%$ with full cellulose conversion over HPA-2 combined with $\mathrm{HCl}$ at $170{ }^{\circ} \mathrm{C}$ and 1 MPa $\mathrm{O}_{2}$ after $9 \mathrm{~h}$ (Table 5, entry 14). ${ }^{136}$ Wu et al. reported an FA yield of $61 \%$ with $100 \%$ cellulose conversion over HPA-2 and $\mathrm{H}_{2} \mathrm{SO}_{4}$ at $180{ }^{\circ} \mathrm{C}$ after $5 \mathrm{~min}$ (Table 5, entry 15). ${ }^{137}$ Wasserscheid et al. obtained 22\% FA from oxidative conversion of cellulose over HPA-2 and $p$-toluenesulfonic acid (TSA) at $90{ }^{\circ} \mathrm{C}$ and $3 \mathrm{MPa} \mathrm{O}_{2}$ after $66 \mathrm{~h}^{138}$ The FA generation over a combination of HPA-2 and p-TSA can be expanded to a wide range of feedstocks including lignocellulose (e.g., xylan, lignin,

Table 5 Oxidation of carbohydrates to formic acid over $\mathrm{H}_{3+n} \mathrm{PV}_{n} \mathrm{Mo}_{12-n} \mathrm{O}_{40}$ (HPA-n)

\begin{tabular}{|c|c|c|c|c|c|c|c|c|c|}
\hline Entry & Substrate & $\begin{array}{l}\text { Feed conc. } \\
\left(\mathrm{mg} \mathrm{mL}{ }^{-1}\right)\end{array}$ & Catalyst & $\begin{array}{l}\text { Temp. } \\
\left({ }^{\circ} \mathrm{C}\right)\end{array}$ & $\mathrm{O}_{2}(\mathrm{MPa})$ & $\begin{array}{l}\text { Time } \\
\text { (h) }\end{array}$ & $\begin{array}{l}\text { Conv. }{ }^{c} \\
(\%)\end{array}$ & $\begin{array}{l}\text { Yield } \\
(\%)\end{array}$ & Ref. \\
\hline 1 & Glucose & 30 & $\mathrm{H}_{5} \mathrm{PV}_{2} \mathrm{Mo}_{10} \mathrm{O}_{40}$ & 80 & 3 & 26 & $>98$ & 47 & 144 \\
\hline 2 & Glucose & 25 & $\mathrm{H}_{5} \mathrm{PV}_{2} \mathrm{Mo}_{10} \mathrm{O}_{40}$ & 100 & 5 (air) & 3 & 100 & 52 & 136 \\
\hline 3 & Glucose & 50 & $\mathrm{H}_{8} \mathrm{PV}_{5} \mathrm{Mo}_{7} \mathrm{O}_{40}$ & 90 & 3 & 8 & 100 & 60 & 135 \\
\hline 4 & Glucose & 18 & $\mathrm{H}_{8} \mathrm{PV}_{5} \mathrm{Mo}_{7} \mathrm{O}_{40}$ & 90 & 2 & 48 & 100 & $85^{a}$ & 141 \\
\hline 5 & Cellobiose & 30 & $\mathrm{H}_{5} \mathrm{PV}_{2} \mathrm{Mo}_{10} \mathrm{O}_{40}$ & 80 & 3 & 26 & $>98$ & 47 & 134 \\
\hline 6 & Glucose & 72 & {$[\mathrm{MIMPS}]_{3} \mathrm{HPMo}_{11} \mathrm{VO}_{40}$} & 180 & 1 & 1 & 100 & 55 & 140 \\
\hline 7 & Sucrose & 30 & $\mathrm{H}_{5} \mathrm{PV}_{2} \mathrm{Mo}_{10} \mathrm{O}_{40}$ & 80 & 3 & 26 & $>98$ & 48 & 134 \\
\hline 8 & Sucrose & 34 & $\mathrm{H}_{8} \mathrm{PV}_{5} \mathrm{Mo}_{7} \mathrm{O}_{40}$ & 90 & 2 & 48 & 96 & $76^{a}$ & 141 \\
\hline 9 & Xylan & 30 & $\mathrm{H}_{5} \mathrm{PV}_{2} \mathrm{Mo}_{10} \mathrm{O}_{40}$ & 80 & 3 & 26 & $\mathrm{~N} / \mathrm{A}$ & 33 & 134 \\
\hline 10 & Xylan & 27 & $\mathrm{H}_{5} \mathrm{PV}_{2} \mathrm{Mo}_{10} \mathrm{O}_{40}+\mathrm{p}-\mathrm{TSA}$ & 90 & 3 & 24 & 97 & 53 & 138 \\
\hline 11 & Xylan & 50 & $\mathrm{H}_{8} \mathrm{PV}_{5} \mathrm{Mo}_{7} \mathrm{O}_{40}+\mathrm{p}-\mathrm{TSA}$ & 90 & 3 & 24 & 100 & 58 & 135 \\
\hline 12 & Cellulose & 30 & $\mathrm{H}_{5} \mathrm{PV}_{2} \mathrm{Mo}_{10} \mathrm{O}_{40}$ & 80 & 3 & 26 & N/A & 1 & 134 \\
\hline 13 & Cellulose & 10 & $\mathrm{H}_{4} \mathrm{PVMO}_{11} \mathrm{O}_{40}$ & 180 & 0.6 & 3 & 100 & 68 & 144 \\
\hline 14 & Cellulose & 10 & $\mathrm{H}_{5} \mathrm{PV}_{2} \mathrm{Mo}_{10} \mathrm{O}_{40}+\mathrm{HCl}$ & 170 & 1 & 9 & 100 & 34 & 136 \\
\hline 15 & Cellulose & 27 & $\mathrm{H}_{5} \mathrm{PV}_{2} \mathrm{Mo}_{10} \mathrm{O}_{40}+\mathrm{H}_{2} \mathrm{SO}_{4}$ & 180 & 3 & 0.08 & 100 & 61 & 137 \\
\hline 16 & Cellulose & 27 & $\mathrm{H}_{5} \mathrm{PV}_{2} \mathrm{Mo}_{10} \mathrm{O}_{40}+\mathrm{p}-\mathrm{TSA}$ & 90 & 3 & 66 & N/A & 22 & 139 \\
\hline 17 & Cellulose & 27 & $\mathrm{H}_{5} \mathrm{PV}_{2} \mathrm{Mo}_{10} \mathrm{O}_{40}+\mathrm{p}-\mathrm{TSA}$ & 90 & 3 & 24 & N/A & 31 & 145 \\
\hline 18 & Cellulose & 50 & $\mathrm{H}_{8} \mathrm{PV}_{5} \mathrm{Mo}_{7} \mathrm{O}_{40}+\mathrm{p}-\mathrm{TSA}$ & 90 & 3 & 24 & 76 & 28 & 135 \\
\hline 19 & Cellulose & 67 & {$[\mathrm{MIMPS}]_{3} \mathrm{HPMo}_{11} \mathrm{VO}_{40}$} & 180 & 1 & 1 & 93 & 51 & 140 \\
\hline 20 & BM cellulose & 10 & $\mathrm{Co}_{0.6} \mathrm{H}_{3.8} \mathrm{PMo}_{10} \mathrm{~V}_{2} \mathrm{O}_{40}$ & 160 & $2\left(\mathrm{O}_{2}+\mathrm{N}_{2}\right)$ & 5 & N/A & 66 & 146 \\
\hline 21 & Lignin & 30 & $\mathrm{H}_{5} \mathrm{PV}_{2} \mathrm{Mo}_{10} \mathrm{O}_{40}$ & 80 & 3 & 26 & N/A & 14 & 134 \\
\hline 22 & Lignin & 27 & $\mathrm{H}_{5} \mathrm{PV}_{2} \mathrm{Mo}_{10} \mathrm{O}_{40}+\mathrm{p}-\mathrm{TSA}$ & 90 & 3 & 24 & N/A & $31-32$ & 138 and 145 \\
\hline 23 & Lignin & 50 & $\mathrm{H}_{8} \mathrm{PV}_{5} \mathrm{Mo}_{7} \mathrm{O}_{40}+\mathrm{p}-\mathrm{TSA}$ & 90 & 3 & 24 & 100 & 32 & 135 \\
\hline 24 & Poplar sawdust & 30 & $\mathrm{H}_{5} \mathrm{PV}_{2} \mathrm{Mo}_{10} \mathrm{O}_{40}$ & 80 & 3 & 26 & N/A & 19 & 134 \\
\hline 25 & Pomace & 33 & $\mathrm{H}_{5} \mathrm{PV}_{2} \mathrm{Mo}_{10} \mathrm{O}_{40}+\mathrm{p}-\mathrm{TSA}$ & 90 & 3 & 24 & N/A & 55 & 139 \\
\hline 26 & Cane trash & 33 & $\mathrm{H}_{5} \mathrm{PV}_{2} \mathrm{Mo}_{10} \mathrm{O}_{40}+\mathrm{p}-\mathrm{TSA}$ & 90 & 3 & 24 & N/A & 49 & 139 \\
\hline 27 & Beech wood & 27 & $\mathrm{H}_{5} \mathrm{PV}_{2} \mathrm{Mo}_{10} \mathrm{O}_{40}+\mathrm{p}-\mathrm{TSA}$ & 90 & 3 & 24 & N/A & 35 & 138 \\
\hline 28 & Beech wood & 16 & $\mathrm{H}_{8} \mathrm{PV}_{5} \mathrm{Mo}_{7} \mathrm{O}_{40}+\mathrm{p}-\mathrm{TSA}$ & 90 & 2 & 48 & N/A & $61^{d}$ & 141 and 145 \\
\hline 29 & Bagasse & 10 & $\mathrm{H}_{4} \mathrm{PVMo}_{11} \mathrm{O}_{40}$ & 180 & 0.6 & 3 & 100 & 61 & 144 \\
\hline 30 & Hay & 10 & $\mathrm{H}_{4} \mathrm{PVMo}_{11} \mathrm{O}_{40}$ & 180 & 2 & 3 & 100 & 55 & 144 \\
\hline
\end{tabular}

${ }^{a}$ Feed conc. $=$ feed concentration. ${ }^{b}$ Temp. $=$ temperature.${ }^{c}$ Conv. $=$ conversation. ${ }^{d}$ Water $: 1$-hexanol $(1: 1)$. 
beech wood, pomace, and cane trash), as well as the thirdgeneration biomass (e.g., algae) (Table 5, entries 10, 16, 22, and 25-27). ${ }^{138,139}$ Similarly, high FA yields from cellulose, xylan, and lignin were obtained over HPA-5 with p-TSA as an additive (Table 5, entries 11, 18 and 23). ${ }^{135}$

The $\mathrm{H}^{+}$cation in HPA- $n$ can be exchanged by organic compounds and transition metal cations. Liu et al. prepared a series of heteropolyanion-based ILs with $\mathrm{PMo}_{11} \mathrm{VO}_{40}{ }^{4-}$ anions and $-\mathrm{SO}_{3} \mathrm{H}$ functionalised cations including $-\mathrm{SO}_{3} \mathrm{H}$ functionalised methylimidazole (MIMPS), $-\mathrm{SO}_{3} \mathrm{H}$ functionalised pyridinium (PyPS) and TEAPS. ${ }^{140}$ The $-\mathrm{SO}_{3} \mathrm{H}$ functionalised cations are responsible for cellulose hydrolysis to glucose, while the $\mathrm{PMO}_{11} \mathrm{VO}_{40}{ }^{4-}$ anions catalyze the glucose oxidation to FA. [MIMPS $]_{3} \mathrm{HPMO}_{11} \mathrm{VO}_{40}$ provided the highest FA yield of $51 \%$ from cellulose at $180^{\circ} \mathrm{C}$ and $1.0 \mathrm{MPa} \mathrm{O}$ (Table 5, entry 19).

Novel process technologies such as in situ extraction of FA are adopted to further increase FA yields. ${ }^{141}$ Albert et al. reported a water-organic biphasic system to effectively boost the FA selectivity compared with monophasic aqueous media. ${ }^{141}$ FA yields of up to $85 \%$ and $61 \%$ were obtained from glucose and beech wood over HPA-5 in the biphasic system (Table 5 entries 4, 8 and 28). The in situ extraction of FA with long-chain primary alcohols such as 1-hexanol and 1-heptanol prevented the decrease of $\mathrm{pH}$ of the aqueous phase, and resulted in a higher FA selectivity and yield.

In addition to Keggin-type POMs, Lindqvist-type isopolyoxometalates $\left[\mathrm{V}_{n} \mathrm{~W}_{6-n} \mathrm{O}_{19}\right]^{x-}$ have also been applied in the biomass oxidation to FA. Albert et al. found that $\mathrm{K}_{5} \mathrm{~V}_{3} \mathrm{~W}_{3} \mathrm{O}_{19}$ selectively oxidised hemicellulose and lignin to FA, while being inactive for cellulose conversion. ${ }^{142,143}$

3.2.1.2 Oxidation of carbohydrates to glycolic acid. Glycolic acid (2-hydroxy acetic acid) is an important C2 $\alpha$-hydroxy acid used as a precursor for the biodegradable polymer polyglycolic acid. ${ }^{147}$ The reaction pathway of carbohydrate conversion to glycolic acid is proposed in Fig. 10. Glucose from the hydrolysis of cellulose undergoes multiple retro-aldol reactions to glycolaldehyde, which is converted to glycolic acid through oxidation. Similarly, fructose from glucose isomerization also undergoes successive retro-aldol reactions and oxidation to provide glycolic acid and FA. ${ }^{148}$ Han et al. reported heteromolybdic acid $\mathrm{H}_{3} \mathrm{PMo}_{12} \mathrm{O}_{40}$ exhibiting high activity for one-pot conversion of $\alpha$-cellulose into glycolic acid. A glycolic acid yield

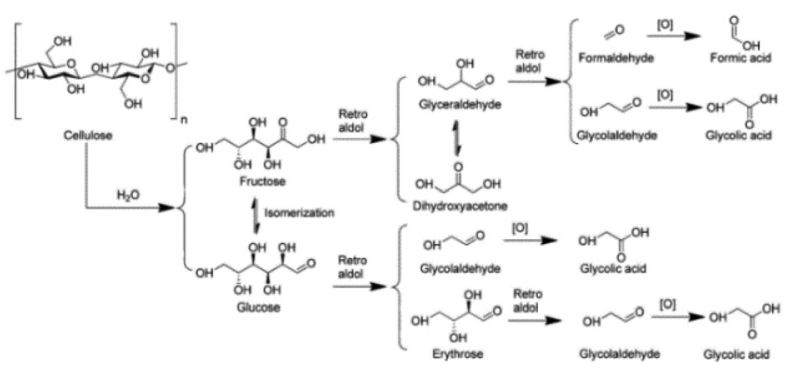

Fig. 10 The proposed reaction pathway for the conversion of cellulose to glycolic acid. ${ }^{148}$ Reproduced from ref. 148 with permission from American Chemical Society, copyright 2012.

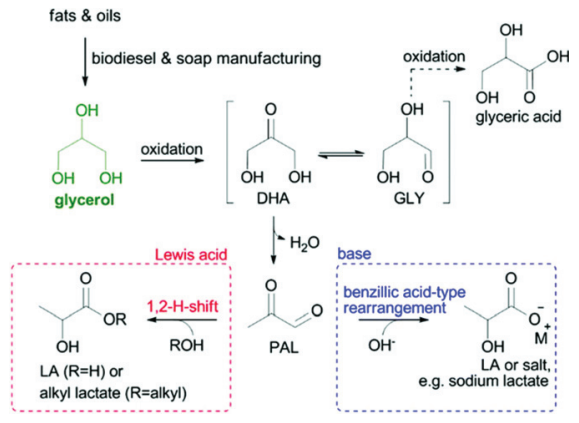

Fig. 11 Catalytic conversion of glycerol to lactic acid or alkyl lactates in water or alcohol, respectively. ${ }^{18}$ Reproduced from ref. 18 with permission from The Royal Society of Chemistry, copyright 2017.

of $49 \%$ together with $10 \%$ FA were obtained at $180{ }^{\circ} \mathrm{C}$ and 0.6 $\mathrm{MPa} \mathrm{O}_{2}$ after 1 h. ${ }^{148}$

3.2.1.3 Oxidation of glycerol to lactic acid. Lactic acid (2-hydroxypropionic acid), as one of the US DOE's top 10 carbohydrate-derived chemicals, has widespread applications in the food, pharmaceutical and chemical industries such as building blocks of biodegradable plastic polylactic acid. ${ }^{18}$ The reaction pathway of glycerol conversion to lactic acid is shown in Fig. 11. Glycerol undergoes dehydration/oxidation to form dihydroxyacetone (DHA) in equilibrium with glyceraldehyde (GCY). The pyruvaldehyde (PAL) obtained from the dehydration of DHA further undergoes a benzylic acid-type rearrangement to provide lactic acid. ${ }^{149}$ The oxidation of glycerol into lactic acid in water over representative POM-based catalysts is summarised in Table 6.

Wang and co-workers reported $\mathrm{H}_{3} \mathrm{PMo}_{12} \mathrm{O}_{40}$ (HPMo) with optimal Brønsted acidic and redox properties exhibiting a lactic acid selectivity of $90 \%$ at $88 \%$ glycerol conversion. HPMo loaded on carbonised willow catkins (HPMo/C) achieved an even higher lactic acid selectivity of $94 \%$ at $98 \%$ glycerol conversion (Table 6). ${ }^{149}$ The preparation of $\mathrm{HPMo} / \mathrm{C}$ catalysts is shown in Fig. 12, including (1) surface oxidation of the carbon support; (2) covalent binding of ethanediamine to the surface carboxylic groups; and (3) functionalization with 1-bromodecane and immobilization of HPMo into a lipid-like layer. The inclusion of HPMo in a lipid-like layer prevents HPMo leaching; thus the HPMo/C exhibits high catalyst stability.

In addition, novel HPMo@lipid(n)/GO catalysts were developed with HPMo embedded in lipid-like bilayers that are covalently bonded to graphene oxide (GO). The coupling of the surface carboxylic groups on functionalised graphene oxide (GO) with diamine provided a covalently linked GO- $\mathrm{NH}_{2}$ monolayer. Then the functionalisation of the $\mathrm{GO}-\mathrm{NH}_{2}$ monolayer with 1-bromodecane, followed by embedding of HPMo into the lipid-like bilayer, provided HPMo@lipid(n)/GO hybrid materials (Fig. 13). ${ }^{150}$ The optimal HPMo@lipid(4)/GO catalyst featured balanced hydrophobic and hydrophilic properties, and the capillary-like microreactor configuration formed by the lipid-like bilayer structure. It achieved a high lactic acid yield of $90 \%$ with a glycerol conversion of $97 \%$ at $60{ }^{\circ} \mathrm{C}$ and 1 
Table 6 Oxidation of glycerol to lactic acid in water over POM-based catalysts

\begin{tabular}{llll}
\hline Catalysts & Reaction conditions $^{a}$ & Yield (\%) & Ref. \\
\hline $30 \% \mathrm{H}_{3} \mathrm{PMo}_{12} \mathrm{O}_{40} / \mathrm{C}$ & $10 / 60 / 5 / 5$ & 92 & 149 \\
$\mathrm{AlPMo}_{12} \mathrm{O}_{40}$ & $10 / 60 / 10 / 5$ & 85 & 151 \\
$\mathrm{Ag}_{3} \mathrm{PMo}_{12} \mathrm{O}_{40}$ & $10 / 60 / 10 / 5$ & 93 & 152 \\
$\mathrm{H}_{3} \mathrm{PMo}_{12} \mathrm{O}_{40} @ l i p i d / G O$ & N/A/60/10/3.5 & 90 & 150
\end{tabular}

${ }^{a}$ Reaction conditions: Catalyst amount (mg $\left.\mathrm{mL}^{-1}\right) /$ reaction temperature ${ }^{\circ} \mathrm{C} /$ oxygen pressure bar/reaction time $\mathrm{h}$.

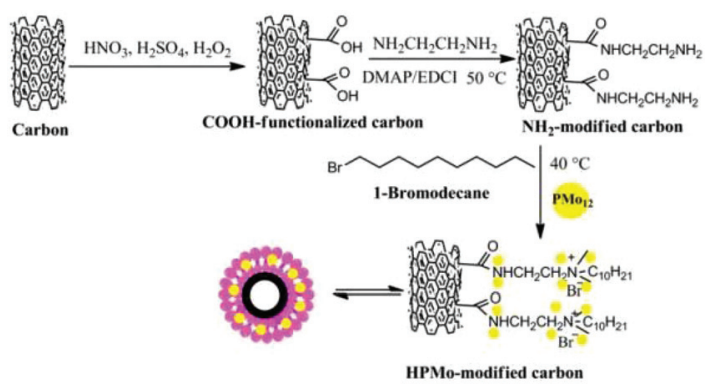

Fig. 12 Synthetic progress of HPMo-modified carbon catalysts. ${ }^{149}$ Reproduced from ref. 149 with permission from WILEY, copyright 2015.

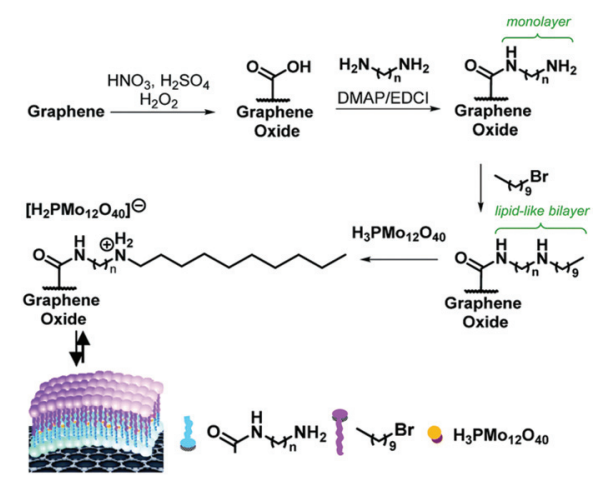

Fig. 13 Synthetic strategy for the assembly of HPMoalipid(n)/GO hybrid catalyst materials, where $n$ represents the length of the diamine carbon chain $\left(n=2,4,6,8\right.$, and 10). ${ }^{150}$ Reproduced from ref. 150 with permission from The Royal Society of Chemistry, copyright 2017.

MPa $\mathrm{O}_{2}$ after $3.5 \mathrm{~h}$ (Table 6). The capillary reactor of HPMo@lipid(n)/GO enhanced the adsorption of glycerol and oxygen molecules, and concentrated them around HPMo, thus improving glycerol conversion. The oxidative ability of HPMo enhanced by GO and optimised by the length of the alkyl chain, combined with the balanced hydrophobicity of the lipid bilayer and the hydrophilicity of HPMo, led to high selectivity to lactic acid.

3.2.1.4 Dehydration-oxidation of glycerol to acrylic acid. Acrolein and acrylic acid (AA) are critical chemicals derived from glycerol. AA is generally obtained by a two-step tandem reaction including glycerol dehydration to acrolein over a solid acid and subsequent oxidation of acrolein over Mo- and

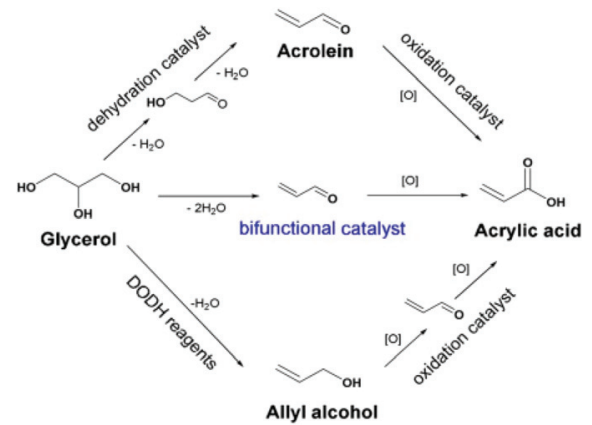

Fig. 14 Two-step and one-step conversion of glycerol to acrylic acid. ${ }^{153}$ Reproduced from ref. 153 with permission from American Chemical Society, copyright 2016.

V-based catalysts (Fig. 14). AA synthesis is also realised via a two-step tandem reaction via allyl alcohol as an intermediate. In this context, the direct oxidative dehydration of glycerol to acrylic acid over bifunctional catalysts is highly desired. Zhang et al. reported that the incorporation of vanadium species into CsPMo and CsPW promoted the formation of acrylic acid from glycerol conversion, due to the synergism between the Keggin anions and the cesium/vanadium species at the secondary structure. The combination of $\mathrm{Cs}(\mathrm{VO})_{0.2} \mathrm{PMo}$ and $\mathrm{Cs}(\mathrm{VO})_{0.2} \mathrm{PW}$ as solid solution catalysts changed the oxidation ability and surface acidity, and improved selectivity for acrylic acid. Consequently, $\mathrm{H}_{0.1} \mathrm{Cs}_{2.5}(\mathrm{VO})_{0.2}\left(\mathrm{PMo}_{12} \mathrm{O}_{40}\right)_{0.25}\left(\mathrm{PW}_{12} \mathrm{O}_{40}\right)_{0.75}$ displayed the highest acrylic acid yield up to $60 \%$ and satisfactory resistance to coke deposition. ${ }^{153}$

3.2.2 Synthesis of furan derivatives. Maleic anhydride (MA) is an important precursor for polyester resins, additives, pharmaceuticals, and so on. Yin et al. reported a vanadium-substituted HPA catalyst $\left(\mathrm{H}_{5} \mathrm{PV}_{2} \mathrm{Mo}_{10} \mathrm{O}_{40}\right)$ for the aerobic oxidation of HMF to maleic anhydride (MA). ${ }^{154}$ An MA yield of $41.8 \%$ and total yields of MA and maleic acid of 50.9\% were achieved under optimised conditions (acetonitrile, $90{ }^{\circ} \mathrm{C}, 10$ bar $\mathrm{O}_{2}$, $8 \mathrm{~h}$ ). A novel mechanism initialised by the $\mathrm{C}-\mathrm{C}$ bond cleavage between the hydroxymethyl group and furan sketch of HMF via an ET-OT process, without the formation of 2,5-diformylfuran (DFF), 5-formyl-2-furancarboxylic acid (FFCA), 2,5-furandicarboxylic acid (FDCA), and 5-hydroxymethyl-2-furancarboxylic acid (HMFCA), was proposed for MA formation (Fig. 15).

\section{Biomass valorisation into renewable chemicals and fuels over metal-POM composites}

Metal NP-POM composites are referred to either metal NPs supported on heterogenised POMs or both metal NPs and POMs immobilised on an additional support. Such an intimate contact between the metal and POMs has the advantage of facilitated migration of the substrate/intermediates between the metal and acid sites at a nanometer distance. This section 


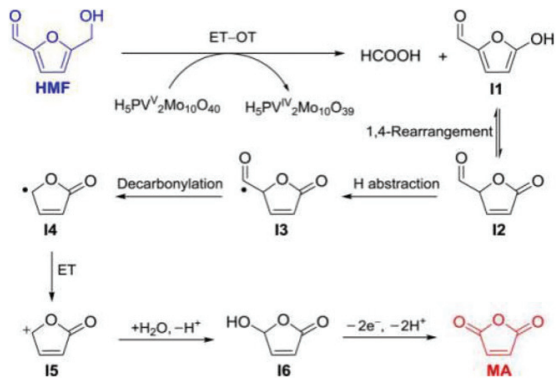

Fig. 15 Oxidation of $\mathrm{HMF}$ into $\mathrm{MA}$ over $\mathrm{H}_{5} \mathrm{PV}_{2} \mathrm{MO}_{10} \mathrm{O}_{40}$, from ref. 155 Reproduced from ref. 155 with permission from Elsevier, copyright 2017.

describes how metal-POMs can be used in catalytic biorefinery to achieve a one-pot tandem catalytic process. The use of physical mixtures of metal catalysts and POMs as catalysts is also included to provide readers a more comprehensive overview.

\subsection{Hydrolysis, hydrogenation and related reactions}

4.1.1 Hydrolysis/hydrogenation of polysaccharides. The hydrolysis of polysaccharides (e.g., cellulose and inulin) and disaccharides (e.g., cellobiose) generates monosaccharides. These monosaccharides undergo hydrogenation to yield hexitols (e.g., sorbitol) as important products in the food, cosmetic and pharmaceutical industries. ${ }^{6}$ Since the pioneering works from Kou, ${ }^{156}$ Liu, ${ }^{157}$ and Fukuoka, ${ }^{158}$ which proved the feasibility of one-pot reaction combining polysaccharide/disaccharide hydrolysis and monosaccharide hydrogenation, many catalytic systems have been developed. In the context of using metal-POM composites as catalysts, several factors including the substrate concentration, ${ }^{159}$ hydrophobicity, ${ }^{160}$ acidity of POMs,${ }^{160-163}$ and size of metal NPs ${ }^{161}$ seem to have great impact on the catalytic activity and product selectivity. The hydrogenation activity is sufficiently higher compared with the hydrolysis rate; thus hydrolysis is generally believed to be the rate-determining step..$^{159,161}$

Sels and co-workers reported the direct combination of $\mathrm{H}_{4} \mathrm{SiW}_{12} \mathrm{O}_{40} / \mathrm{H}_{3} \mathrm{PW}_{12} \mathrm{O}_{40}{ }^{159}$ or water-tolerant $\mathrm{Cs}_{3.5} \mathrm{H}_{0.5} \mathrm{SiW}_{12} \mathrm{O}_{40}$ $(\mathrm{CsSiW}) / \mathrm{Cs}_{2.5} \mathrm{H}_{0.5} \mathrm{PW}_{12} \mathrm{O}_{40}$ (CsPW) ${ }^{160}$ with $\mathrm{Ru} / \mathrm{C}$ to convert cellulose to hexitols. Palkovits et al. adopted physical mixtures of $\mathrm{H}_{4} \mathrm{SiW}_{12} \mathrm{O}_{40} / \mathrm{H}_{3} \mathrm{PW}_{12} \mathrm{O}_{40}$ and $\mathrm{Ru} / \mathrm{C}$ for the transformation of cellulose and biomass feedstock spruce to sugar alcohols. High yields of $\mathrm{C}_{4}-\mathrm{C}_{6}$ sugar alcohols up to $81 \%$ and $65 \%$ were obtained at $160{ }^{\circ} \mathrm{C}$ starting from cellulose and spruce, respectively. ${ }^{163}$

Wang and co-workers reported $\mathrm{Ru} / \mathrm{Cs}_{3} \mathrm{PW}_{12} \mathrm{O}_{40}$ catalysts for the transformation of cellobiose and cellulose into sorbitol. ${ }^{162}$ $\mathrm{Ru} / \mathrm{Cs}_{3} \mathrm{PW}_{12} \mathrm{O}_{40}$ catalysts exhibited full cellobiose conversion, and a high sorbitol yield of $86 \%$ at $140{ }^{\circ} \mathrm{C}$. It is proposed that the reversible Brønsted acid sites were generated on the $\mathrm{Cs}_{3} \mathrm{PW}_{12} \mathrm{O}_{40}$ surface by spillover $\mathrm{H}$ species from $\mathrm{H}_{2}$ dissociation on Ru NPs. ${ }^{162}$ However, the surface area and porosity of $\mathrm{Cs}_{x} \mathrm{H}_{3-x} \mathrm{PW}_{12} \mathrm{O}_{40}$ are relatively low, leading to inefficient diffusion of the reactant and product.

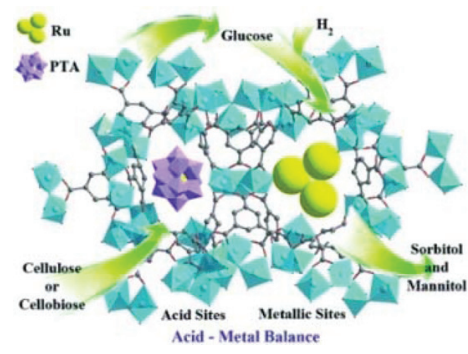

Fig. 16 Metal-acid bifunctional catalyst Ru-PTA/MIL-100(Cr) for the conversion of cellulose and cellobiose into sorbitol. ${ }^{164}$ Reproduced from ref. 164 with permission from WILEY, copyright 2013.

Chen et al. encapsulated PTA $\mathrm{H}_{3} \mathrm{PW}_{12} \mathrm{O}_{40}$ inside the mesoporous cavities of MIL-100(Cr), and developed a Ru-PTA/ MIL-100(Cr) catalyst to convert cellulose and cellobiose into sorbitol (Fig. 16). ${ }^{164}$ The ratio of the acid site density to the number of Ru surface atoms $\left(n_{\mathrm{A}} / n_{\mathrm{Ru}}\right)$ in the catalytic performance was analysed in detail. The optimum $n_{\mathrm{A}} / n_{\mathrm{Ru}}$ values between 8.84 and 12.90 led to the maximum conversion of cellulose and cellobiose into sorbitol. The Ru-PTA/MIL-100(Cr) catalysts with optimal acid/metal ratios exhibited high sorbitol yields of $97.1 \%$ and $57.9 \%$ at full cellobiose and cellulose conversion, respectively. However, the Ru-PTA/MIL-100(Cr) catalysts suffered from poor reusability, which might have resulted from the adsorption of insoluble substances such as oligomeric products on catalysts.

Isosorbide, a precursor of various biopolymers, pharmaceuticals and other chemicals, is obtained from the combined hydrolytic hydrogenation of cellulose to sorbitol and further dehydration of sorbitol. ${ }^{18}$ Sels and co-workers reported such an approach using a physical mixture of $\mathrm{H}_{4} \mathrm{SiW}_{12} \mathrm{O}_{40}$ and $\mathrm{Ru} / \mathrm{C}$. $52 \%$ isosorbide was obtained from purified microcrystalline cellulose, while $63 \%$ isosorbide was generated from crude wheat straw pulps obtained by organosolv fractionation. ${ }^{165}$

The hydrolysis of polysaccharides and subsequent hydrogenolysis with $\mathrm{C}-\mathrm{C}$ and $\mathrm{C}-\mathrm{O}$ cleavage can provide high value diols such as ethylene glycol (EG) and propylene glycol (PG). ${ }^{18}$ For instance, García-Bosch et al. reported a Ru-STA/AC catalyst to achieve a 1,2-PDO yield of $40 \%$ and selectivity up to $50 \%$ from fructose at $140{ }^{\circ} \mathrm{C} .{ }^{166} \mathrm{Zhang}$ and co-workers reported the combination of RANEY® nickel and W species for EG synthesis. The EG yield increased in the following order: $\mathrm{H}_{4} \mathrm{SiW}_{12} \mathrm{O}_{40}<\mathrm{H}_{3} \mathrm{PW}_{12} \mathrm{O}_{40}<\mathrm{WO}_{3}<\mathrm{H}_{2} \mathrm{WO}_{4}$ (Fig. 17). ${ }^{167}$ The W species catalysed the cleavage of the $\mathrm{C}-\mathrm{C}$ bonds in cellulose by a retro-aldol reaction pathway to generate glycolaldehyde, which undergoes further hydrogenation to form EG. ${ }^{167-170}$ Similarly, Guerrero-Ruiz et al. adopted Ru NPs supported on an HPA-carbon material [activated carbon (AC), high surface area graphite (HSAG)] for the hydrolytic hydrogenolysis of cellulose to alkanediols. ${ }^{171}$ Among the various POMs tested, $\mathrm{Ru} /$ AC-HPA and Ru/HSAG-HPA catalysts based on tungsten-based HPA (PTA and STA) exhibited better performance in terms of EG selectivity. 


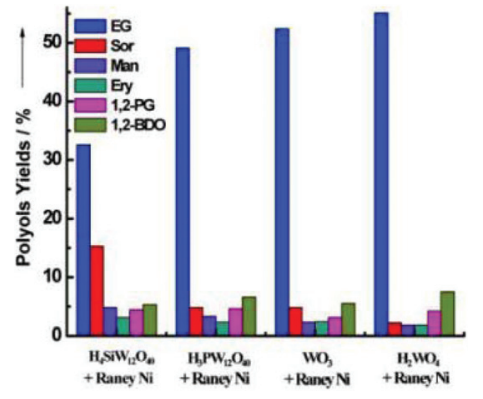

Fig. 17 Catalytic performance of different binary catalysts composed of tungsten-based compounds with RANEY ${ }^{\circ} \mathrm{Ni}$. The reactions were performed with cellulose $(0.5 \mathrm{~g})$, water $(50 \mathrm{~mL})$, RANEY® ${ }^{\circ} \mathrm{Ni}(40-50 \mathrm{mg})$, and a W compound $(50 \mathrm{mg})$ at $245{ }^{\circ} \mathrm{C}$ and $6 \mathrm{MPa} \mathrm{H}_{2}$ for $0.5 \mathrm{~h}^{167}$ Reproduced from ref. 167 with permission from WILEY, copyright 2013.

4.1.2 Hydrolysis/hydrogenation of 5-hydroxymethylfurfural/furfural. HMF is obtained from acid-catalysed dehydration of carbohydrates. A variety of fuels and commodity chemicals such as FDCA, ${ }^{18}$ DFF, 2,5-dimethylfuran (2,5-DMF) and alkyl levulinate are further produced from $\mathrm{HMF}^{34}$ For instance, selective hydrogenation-hydrogenolysis of HMF provided 2,5-DMF (Fig. 18), which is a potential substitute for ethanol and other fossil energy sources. Yadav et al. reported a Pd- $\mathrm{Cs}_{2.5} \mathrm{H}_{0.5} \mathrm{PW}_{12} \mathrm{O}_{40} / \mathrm{K}-10$ clay that exhibited $98 \%$ conversion of $\mathrm{HMF}$ with $81 \%$ selectivity to $2,5-\mathrm{DMF}$ under mild reaction conditions $\left(90^{\circ} \mathrm{C}, 1 \mathrm{MPa} \mathrm{H}_{2}\right) \cdot{ }^{172} \mathrm{H}_{2}$ was dissociatively adsorbed on Pd sites, and the aldehyde group of HMF was hydrogenated into the hydroxyl group, thus generating bis(hydroxymethyl) furan (BHMF) as an intermediate. Further hydrogenolysis of the hydroxyl groups of BHMF to 2,5-DMF was facilitated by the acid sites of the $\mathrm{Cs}_{2.5} \mathrm{H}_{0.5} \mathrm{PW}_{12} \mathrm{O}_{40} / \mathrm{K}-10$ clay.

While HMF is a key platform chemical from cellulose, furfural is an important platform molecule derived from hemicellulose for the synthesis of value-added products including furfuryl alcohol (FAL) and alkyl levulinate (AL). Furfural hydrogenation into intermediate FAL and subsequent acid-catalysed alcoholysis of FAL provide AL as an important bio-based fuel additive and a precursor for $\gamma$-valerolactone (Fig. 19). The Au$\mathrm{HSiW} / \mathrm{ZrO}_{2}$ catalyst achieved a high $\mathrm{AL}$ yield of $80.2 \%$ with full furfural conversion at $100{ }^{\circ} \mathrm{C} .{ }^{173}$ The Au surface sites catalysed the transfer hydrogenation reaction of furfural to FAL using 2-propanol as a H-donor, while the acidic HSiW sites catalysed

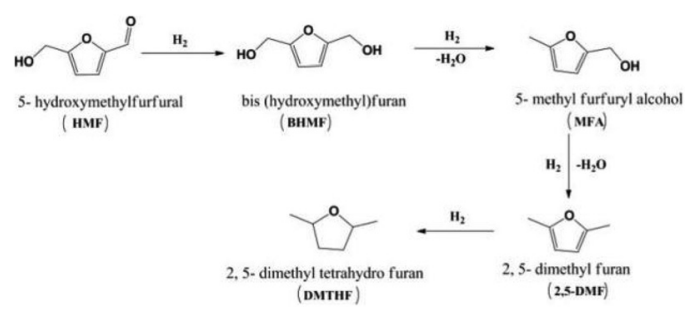

Fig. 18 Selective hydrogenation of 5-hydroxymethylfurfural to 2,5dimethyl furan. ${ }^{172}$ Reproduced from ref. 172 with permission from American Chemical Society, copyright 2016.

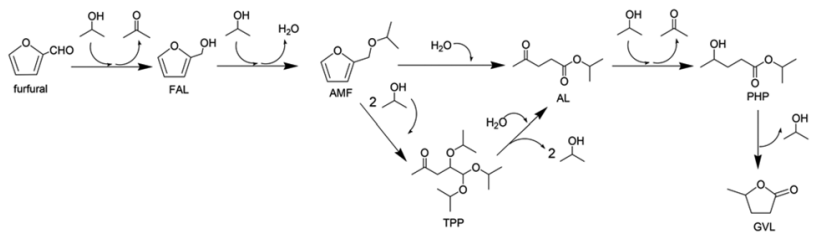

Fig. 19 Conversion of furfural to alkyl levulinate with 2-propanol as the $\mathrm{H}$-donor. ${ }^{173}$ Reproduced from ref. 173 with permission from The Royal Society of Chemistry, copyright 2016.

the alcoholysis of FAL to yield AL. Among HSiW/HPW/HPMo impregnated, $\mathrm{ZrO}_{2}$ supported Au catalysts, a linear relationship between the acidity of $\mathrm{Au}-\mathrm{HPA} / \mathrm{ZrO}_{2}$ catalysts and $\mathrm{AL}$ yield was established.

4.1.3 Hydrogenolysis/dehydration of glycerol to diol/acrolein. The biodiesel production via transesterification of plant oils and animal fats with short chain alcohols generates a large amount of glycerol as a by-product. Thus, the transformation of bioglycerol into value-added chemicals via hydrogenolysis, dehydration, and other reactions is of significance. In particular, the selective hydrogenolysis of glycerol to valueadded C3 chemicals including 1,2-propanediol (1,2-PDO), ${ }^{174}$ 1,3-propanediol (1,3-PDO), ${ }^{175,176}$ and propanols ${ }^{177-179}$ is promising to valorize the surplus glycerol. ${ }^{23,24,180}$ The dehydration of glycerol to 3-hydroxypropaldehyde (3-HPA) on Brønsted acid sites followed by subsequent hydrogenation on the metal center lead to the formation of 1,3-PDO. ${ }^{175,176}$ The dehydration of glycerol into acetol over either metal sites or Lewis acid sites and consecutive hydrogenation over metal sites (e.g. Ru and $\mathrm{Cu}$ ) result in the formation of $1,2-\mathrm{PDO}^{.24} 1$-Propanol is usually formed via 1,2-PDO as an intermediate (Fig. 20). ${ }^{177}$ 1,3-PDO has the highest economic value among the three, and functions as a monomer to make polypropylene terephthalate as polyester fibers.

A series of alkaline metals, including $\mathrm{Li}, \mathrm{K}, \mathrm{Rb}$ and $\mathrm{Cs}$, were used to modify the $\mathrm{Pt}-\mathrm{H}_{4} \mathrm{SiW}_{12} \mathrm{O}_{40} / \mathrm{ZrO}_{2}$ catalyst. $\mathrm{Li}^{+}$exhibited the best promotional effect in glycerol hydrogenolysis, providing $53.6 \%$ 1,3-PDO selectivity and $43.5 \%$ glycerol conversion at $180{ }^{\circ} \mathrm{C}, 5 \mathrm{MPa}$ (Table 7). ${ }^{175} \mathrm{~A}$ linear relationship between 1,3PDO yield and concentration of Brønsted acid sites was observed, indicating that the hydrogenolysis of glycerol to 1,3PDO proceeded via dehydration of glycerol to 3-HPA on

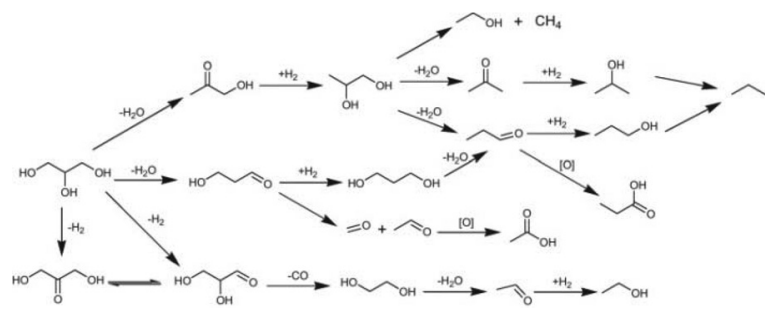

Fig. 20 Reaction scheme of glycerol hydrogenolysis and degradation reactions. ${ }^{177}$ Reproduced from ref. 177 with permission from The Royal Society of Chemistry, copyright 2012. 
Table 7 Hydrogenolysis and dehydration of aqueous glycerol over metal NP-POM bifunctional catalysts

\begin{tabular}{|c|c|c|c|c|c|c|c|c|c|c|}
\hline Catalysts & $\begin{array}{l}\mathrm{H}_{2} \\
(\mathrm{MPa})\end{array}$ & $\begin{array}{l}\text { Temp. } \\
\left({ }^{\circ} \mathrm{C}\right)\end{array}$ & $\begin{array}{l}\text { Time } \\
\text { (h) }\end{array}$ & $\begin{array}{l}\text { WHSV } \\
\left(\mathrm{h}^{-1}\right)\end{array}$ & $\begin{array}{l}\text { Conv. }{ }^{b} \\
(\%)\end{array}$ & $\begin{array}{l}\text { Sel. }^{c} \\
(1,2-\mathrm{PD})\end{array}$ & $\begin{array}{l}\text { Sel. }^{c} \\
(1,3-\mathrm{PD})\end{array}$ & $\begin{array}{l}\text { Sel }^{c} \\
(1-\mathrm{PrOH})\end{array}$ & $\begin{array}{l}\text { Sel. }^{c} \\
\text { (acrolein) }\end{array}$ & Ref. \\
\hline 5 wt $\% \mathrm{Ru} / \mathrm{C}(3 \mathrm{wt} \%)+15$ wt $\% \mathrm{PTA} / \mathrm{ZrO}_{2}(6 \mathrm{wt} \%)$ & 6 & 180 & 8 & - & 44 & 64.3 & - & - & - & 174 \\
\hline $1 \mathrm{wt} \% \mathrm{Pt}-20 \mathrm{wt} \% \mathrm{Li}_{2} \mathrm{H}_{2} \mathrm{SiW} / \mathrm{ZrO}_{2}$ & 5 & 180 & - & 0.09 & 43.5 & 14.2 & 53.6 & 24.1 & - & 175 \\
\hline $2 \mathrm{wt} \% \mathrm{Pt}-15 \mathrm{wt} \% \mathrm{H}_{4} \mathrm{SiW}_{12} \mathrm{O}_{40} / \mathrm{ZrO}_{2}$ & 5 & 180 & - & 0.09 & 24.1 & 16.5 & 48.1 & 21.8 & - & 177 \\
\hline $2 \mathrm{wt} \% \mathrm{Pt}-15 \mathrm{wt} \% \mathrm{H}_{4} \mathrm{SiW}_{12} \mathrm{O}_{40} / \mathrm{ZrO}_{2}$ & 5 & 200 & - & 0.05 & 99.7 & 5.1 & 0.9 & 80.0 & - & 177 \\
\hline $2 \mathrm{wt} \% \mathrm{Pt}-15 \mathrm{wt} \% \mathrm{H}_{3} \mathrm{PW}_{12} \mathrm{O}_{40} / \mathrm{ZrO}_{2}$ & 0.1 & 250 & - & 1.02 & 98.6 & - & - & 97 & - & 178 \\
\hline $0.5 \mathrm{wt} \% \mathrm{Pd} / \mathrm{Cs}_{2.5} \mathrm{H}_{0.5} \mathrm{PW}_{12} \mathrm{O}_{40}$ & 0.1 & 275 & 5 & 2.80 & 79 & - & - & - & 96 & 182 \\
\hline $1 \mathrm{wt} \% \mathrm{Pd}-30 \mathrm{wt} \% \mathrm{H}_{3} \mathrm{PW}_{12} \mathrm{O}_{40} / \mathrm{C}$ & 0.1 & 260 & 7 & 0.08 & 90 & - & - & - & 70 & 182 \\
\hline 2 wt $\% \mathrm{Pd}-30 \mathrm{wt} \% \mathrm{H}_{3} \mathrm{PW}_{12} \mathrm{O}_{40} / \mathrm{Zr}-\mathrm{MCM}-41$ & 0.1 & 320 & 5 & 0.35 & 90 & - & - & - & 83 & 83 \\
\hline
\end{tabular}

Brønsted acid sites followed by hydrogenation of the dehydration product 3-HPA on nearby metal sites. Furthermore, Pt$\mathrm{HSiW} / \mathrm{ZrO}_{2}$ exhibited superior performance in glycerol hydrogenolysis to 1,3-propanediol among HSiW, HPW and HPMo modified $\mathrm{Pt} / \mathrm{ZrO}_{2}$ catalysts, due to the higher concentration of Brønsted acid sites. ${ }^{175}$ In parallel, a close correlation between the 1,2-PDO yield and the concentration of Lewis acid sites was obtained. Thus, the Brønsted acid sites are proposed to facilitate the selective generation of 1,3-PDO, while the Lewis acid sites favor the generation of 1,2-PDO.

$\mathrm{Zhu}$ and co-workers reported that the $\mathrm{Pt}-\mathrm{H}_{4} \mathrm{SiW}_{12} \mathrm{O}_{40} / \mathrm{ZrO}_{2}$ catalyst afforded a high 1-propanol yield of $80 \%$ and long-term stability of $160 \mathrm{~h}$ at $200{ }^{\circ} \mathrm{C}$ and $5 \mathrm{MPa} \mathrm{H}_{2}$ (Table 7). ${ }^{177}$ The Pt$\mathrm{H}_{4} \mathrm{SiW}_{12} \mathrm{O}_{40} / \mathrm{ZrO}_{2}$ catalyst exhibited higher activity and propanol selectivity than its counterparts with $\mathrm{Pd}, \mathrm{Cu}$, and $\mathrm{Ni}$ as metal sites. $\mathrm{ZrO}_{2}$ interacts strongly with Pt sites, and prevents the crystallisation of Pt NPs in calcination at high temperatures. The small Pt particle size with high exposure of the Pt active species on the surface resulted in superior activity of Pt$\mathrm{H}_{4} \mathrm{SiW}_{12} \mathrm{O}_{40} / \mathrm{ZrO}_{2}$. The Pt- $\mathrm{H}_{4} \mathrm{SiW}_{12} \mathrm{O}_{40} / \mathrm{ZrO}_{2}$ catalysts also displayed high resistance to the impurities in crude glycerol.

Acrolein, an important precursor for the production of adhesives, polymers, and detergents, can be obtained via the dehydration of glycerol over POMs/HPAs. $\mathrm{H}_{2}$ co-feeding and incorporation of platinum-group metals prevent coking and enhance the catalyst stability. ${ }^{73,181} \mathrm{Pd}$ incorporation showed a larger stability enhancement effect than the incorporation of its Pt and $\mathrm{Ru}$ counterparts. ${ }^{83,182}$ For instance, $\mathrm{Pd}-\mathrm{H}_{3} \mathrm{PW}_{12} \mathrm{O}_{40} /$ Zr-MCM-41 exhibited high catalytic activity and stability, showing a slight decrease of glycerol conversion from $97 \%$ to $87 \%$ after 50 h. ${ }^{83}$

\subsection{Oxidation of carbohydrates and derivatives}

The hydrolysis of cellulose and cellobiose and further oxidation lead to the generation of gluconic acid, an important food additive and intermediate for the synthesis of fine chemicals and pharmaceuticals. ${ }^{6}$ For metal NP-POM nanocomposites, the acidic sites facilitate the hydrolysis of cellulose and cellobiose to glucose, while the metal (usually Au) NPs facilitate the oxidation of glucose into gluconic acid (Fig. 21). Han et al. reported a $\mathrm{Au} / \mathrm{Cs}_{2} \mathrm{HPW}_{12} \mathrm{O}_{40}$ acidic/oxidative bifunctional catalyst, achieving a high gluconic acid yield of $96.4 \%$

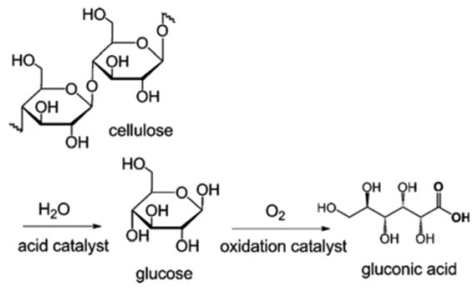

Fig. 21 Direct conversion of cellulose into gluconic acid by using hydrolysis and oxidation reactions. ${ }^{184}$ Reproduced from ref. 184 with permission from WILEY, copyright 2012.

with nearly complete cellobiose conversion. ${ }^{183} \mathrm{Cs}_{2} \mathrm{HPW}_{12} \mathrm{O}_{40}$ was inert to the deep oxidation of gluconic acid, and passivated the oxidative activity of $\mathrm{Au} \mathrm{NPs}$; thus $\mathrm{Au} / \mathrm{Cs}_{2} \mathrm{HPW}_{12} \mathrm{O}_{40}$ nanocomposites effectively prevented over-oxidation of gluconic acid. XPS analysis and DFT calculations demonstrated that the strong metal-support interfacial interaction effectively modulates the electronic structures of Au NPs, and subsequently the reactivity of the active oxygen species on the $\mathrm{Au}$ surface, thus resulting in the selective oxidation to gluconic acid. Several $\mathrm{Au} / \mathrm{Cs}_{x} \mathrm{H}_{3-x} \mathrm{PW}_{12} \mathrm{O}_{40}$ catalysts were developed for the same reaction. $97 \%$ gluconic acid was attained over $\mathrm{Au} /$ $\mathrm{Cs}_{1.2} \mathrm{H}_{1.8} \mathrm{PW}_{12} \mathrm{O}_{40}$, which bears stronger acidity and smaller $\mathrm{Au}$ NP size compared to other samples, at $145{ }^{\circ} \mathrm{C}$ for $3 \mathrm{~h}^{184}$ Indeed, both the acidity of POMs and mean-size of the Au NPs are crucial parameters in the conversion of cellobiose into gluconic acid. $\mathrm{Cs}_{x} \mathrm{H}_{3-x} \mathrm{PW}_{12} \mathrm{O}_{40}$ with stronger acidity not only facilitated the conversion of cellobiose, but also accelerated the desorption of gluconic acid and inhibited the consecutive degradation. The Au NPs with smaller size accelerated the oxidation of glucose, leading to high selectivity for gluconic acid.

\subsection{Hydrodeoxygenation/deoxygenation of biomass-derived oxygenates}

Due to the high oxygen content in biomass feedstock, hydrodeoxygenation (HDO) is an effective method to remove (part of) oxygen to convert biomass-derived oxygenates into drop-in bio-fuels and chemicals. ${ }^{20,29,30}$ The HDO process generally involves a combination of different reactions including hydrolysis, hydrogenation, hydrogenolysis, dehydration, decarboxylation and decarbonylation. ${ }^{29}$ Based on the structures of sub- 
strates, the HDO process can be mainly classified into the HDO of ketones, ${ }^{185,186}$ ethers, ${ }^{188}$ carboxylic acids, ${ }^{189}$ esters, ${ }^{188}$ angelica lactones, ${ }^{190}$ furanic compounds, ${ }^{191}$ carbohydrates, ${ }^{192}$ and aromatic compounds. ${ }^{186,188}$

For the HDO of aliphatic and aromatic ketones, the reaction pathway involves the hydrogenation of ketones to a secondary alcohol on metal sites (mostly Pt) followed by dehydration of the alcohol to alkene on acid sites, and finally hydrogenation of the alkene to alkane on metal sites. ${ }^{185-187}$ Kozhevnikov et al. investigated the gas-phase deoxygenation of aromatic ether anisole, aliphatic diisopropyl ether (DPE), and aliphatic ester ethyl propanoate (EP) over bifunctional catalysts comprising $\mathrm{Pt}, \mathrm{Ru}, \mathrm{Ni}$, and $\mathrm{Cu}$ as the metal components and $\mathrm{Cs}_{2.5} \mathrm{H}_{0.5} \mathrm{PW}_{12} \mathrm{O}_{40}$ as the acid component (Fig. 22). ${ }^{188}$ For the HDO of anisole, the model compound of lignin, consecutive hydrogenation of the aromatic ring, elimination of methanol

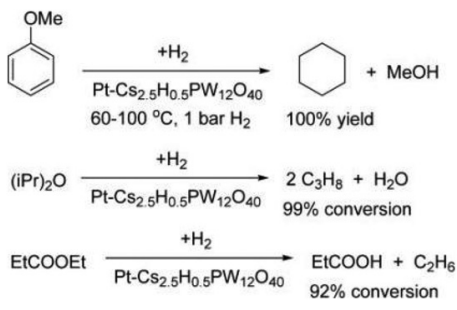

Fig. 22 Deoxygenation of ethers and esters over a bifunctional Pt-HPA catalyst in the gas phase. ${ }^{188}$ Reproduced from ref. 188 with permission from American Chemical Society, copyright 2016.

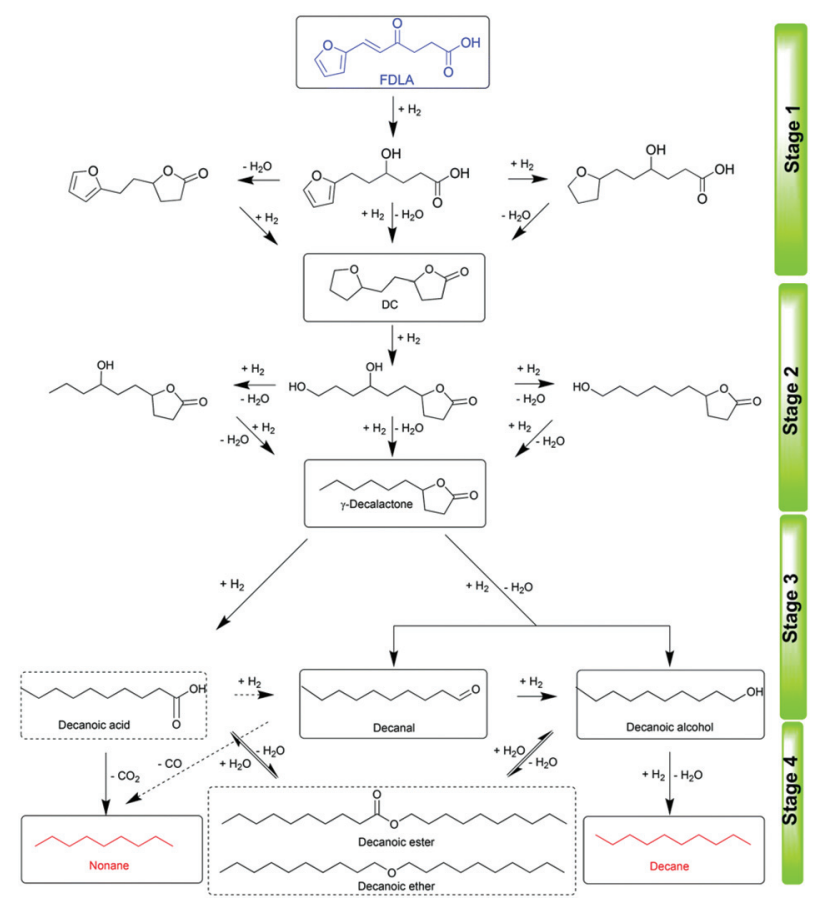

Fig. 23 Proposed reaction pathway for the HDO of FDLA. ${ }^{191}$ Reproduced from ref. 191 with permission from The Royal Society of Chemistry, copyright 2020. from methoxylcyclohexane, and further hydrogenation to cyclohexane can be facilitated by bifunctional catalysts. $0.5 \%$ $\mathrm{Pt} / \mathrm{Cs}_{2.5} \mathrm{H}_{0.5} \mathrm{PW}_{12} \mathrm{O}_{40}$ achieved a high cyclohexane selectivity of $89 \%$ with an anisole conversion of $87 \%$ under mild conditions $\left(100{ }^{\circ} \mathrm{C}\right.$ and 1 bar of $\mathrm{H}_{2}$ ), and the physical mixture of $\mathrm{Pt} / \mathrm{C}$ and $\mathrm{Cs}_{2.5} \mathrm{H}_{0.5} \mathrm{PW}_{12} \mathrm{O}_{40}(0.35 \%$ Pt content) provided $100 \%$ yield of cyclohexane. The Pt/C $+\mathrm{Cs}_{2.5} \mathrm{H}_{0.5} \mathrm{PW}_{12} \mathrm{O}_{40}$ physical mixture displayed higher activity and resistance to deactivation than $\mathrm{Pt} /$ $\mathrm{Cs}_{2.5} \mathrm{H}_{0.5} \mathrm{PW}_{12} \mathrm{O}_{40}$. For the deoxygenation of DPE, the combined $\mathrm{Pt} / \mathrm{C}+\mathrm{Cs}_{2.5} \mathrm{H}_{0.5} \mathrm{PW}_{12} \mathrm{O}_{40}$ catalysts achieved an increased DPE conversion of $99 \%$ and a propane selectivity of $93 \%$. Similarly, for the deoxygenation of EP, the $\mathrm{Pt} / \mathrm{Cs}_{2.5} \mathrm{H}_{0.5} \mathrm{PW}_{12} \mathrm{O}_{40}$ catalyst under $\mathrm{H}_{2}$ showed much better stability compared with $\mathrm{Cs}_{2.5} \mathrm{H}_{0.5} \mathrm{PW}_{12} \mathrm{O}_{40}$, due to the decreased catalyst coking in the presence of $\mathrm{Pt}$ and $\mathrm{H}_{2}$.

Recently, interest in the one-pot HDO of furan derivatives and carbohydrates to alkanes has considerably increased. Zhang et al. reported the first one-pot HDO of high carbon furans (HCFs) and $\delta$-furfurylidenelevulinic acid (FDLA) to long-chain alkanes over $\mathrm{Pd} / \mathrm{C}$ combined with HPW. ${ }^{191}$ The total yield of alkanes as high as $93.2 \%$ including an $89.5 \%$ yield of decane was obtained under relatively mild conditions (3 $\mathrm{MPa} \mathrm{H}_{2}, 170{ }^{\circ} \mathrm{C}, 4 \mathrm{~h}$ ). The consecutive pathways include (a)

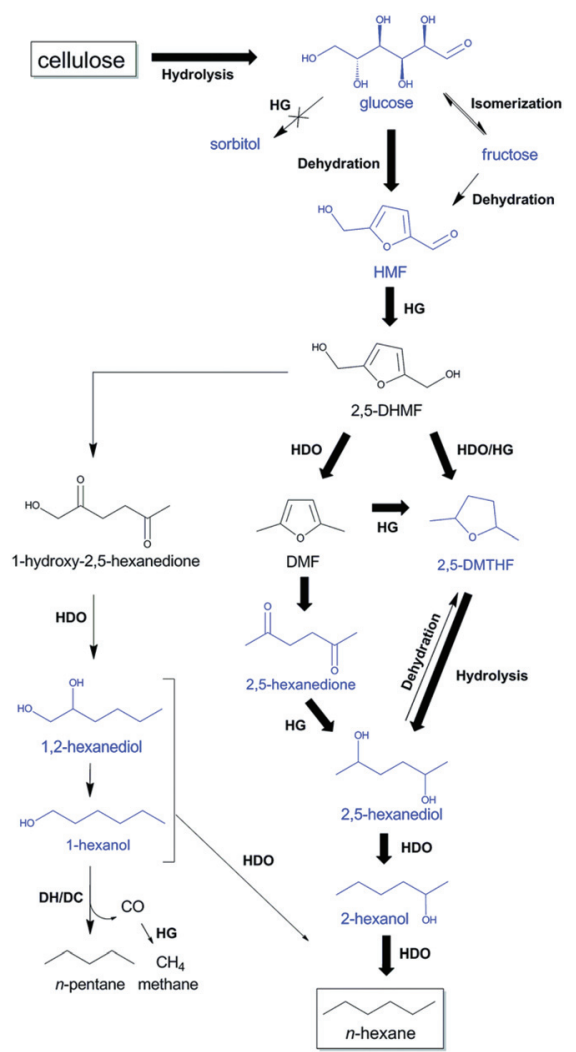

Fig. 24 Proposed reaction pathways from cellulose to $n$-hexane and $n$-pentane through HMF with TSA and htTSA-Ru/C. The most selective reaction pathway from cellulose to $n$-hexane is indicated with bold arrows. HDO, hydrodeoxygenation; HG, hydrogenation; and DH/DC, dehydrogenation/decarbonylation. Reproduced from ref. 192 with permission from The Royal Society of Chemistry, copyright 2015. 
the hydrogenation of unsaturated alkenyls, keto-carbonyls and furans of FDLA over metal sites, (b) the formation of a 5-(2(tetrahydrofuran-2-yl)ethyl)-dihydrofuran-2(3H)-one (DC) intermediate via the intramolecular dehydration reaction, (c) the hydrogenolysis and HDO of furans and lactones over metalacid sites, and (d) the generation of alkanes via HDO of aldehyde/alcohol via hydrogenation-dehydration-hydrogenation steps (Fig. 23).

One-pot conversion of cellulose to $n$-hexane has also been studied. Sels and co-workers reported the combination of tungstosilicic acid (TSA) and hydrothermally TSA-treated Ru/C (ht-STA-Ru/C) catalysts to convert microcrystalline cellulose into $52 \% n$-hexane in a biphasic decane/water system. ${ }^{192}$ The direct conversion of cellulose to straight-chain alkanes mainly proceeded via HMF rather than sorbitol as an intermediate. This is in contrast to the widely accepted pathway, in which hydrolytic hydrogenation of cellulose to sorbitol and consecutive HDO to $n$-hexane is proposed. The kinetic study indicated that the hydrothermal treatment of $\mathrm{Ru} / \mathrm{C}$ with TSA effectively enhanced the selectivity towards HMF hydrogenation and suppressed the glucose hydrogenation ability. The cellulose hydrolysis to glucose, dehydration of glucose to $\mathrm{HMF}$, ring opening hydrolysis of 2,5-dimethylfuran (DMF) to 2,5-hexanedione, as well as ring-opening hydrolysis of 2,5-dimethyltetrahydrofuran (2,5-DMTHF) to 2,5-hexanediol were favoured over TSA in the aqueous phase, while the hydrogenation of the intermediates to the straight-chain alkanes was facilitated over ht-STA-Ru/C (Fig. 24).

\section{Conclusions and outlook}

Recent progress in the chemocatalytic conversion of biomass into chemicals and fuels over POMs and POM-metal composites are summarised. For biomass valorisation over POMs, the advances of acid catalysis and chemical oxidation are discussed. For biomass valorisation over metal-POM composites, an overview of the types of tandem reactions enabled by a metal-POM combination is presented. Despite these encouraging developments, there are still considerable challenges/ opportunities ahead for biomass valorisation using POMbased catalysts.

As shown in this review, a variety of methods have been adopted to transform POMs into insoluble solids or immobilize POMs on porous supports so that they can be used as recyclable heterogeneous catalysts. However, leaching still seems to be a common issue, thus compromising the catalyst stability. Future efforts should be directed to the detailed study of the POM-support interaction, and the kinetics and thermodynamics of POM adsorption/desorption on various support materials. Furthermore, new combinations of POMs anchored on emerging porous materials, such as nitrides, carbides, covalent organic frameworks (COFs), and porous organic frameworks (POFs), may be studied.

In addition, most of the reported POMs for biomass utilisation are focused on the Keggin and Wells-Dawson-type
POMs, and there is still unexplored potential for application of POMs with other structures (e.g., Lindqvist-type). Due to the tunable Brønsted/Lewis-acidity and redox properties, the POMs are generally applied in acid catalysis and chemical oxidation for biomass valorisation, while POM-metal composites are widely applied in the related tandem reactions. Beyond these, attention can be paid to explore other types of reactions in biomass valorisation over POM-based catalysts. For instance, it is envisaged that tungsten-containing POMs are active for retro-aldol condensation to break $\mathrm{C}-\mathrm{C}$ linkages in carbohydrates. Metal-POM composites should also be effective in making organonitrogen chemicals, which appears to be a new direction in biomass conversion. ${ }^{193-195}$

POMs have been proven as effective supports to stabilize a range of single atom catalysts (SACs), ${ }^{196,197}$ exhibiting excellent performance in CO oxidation, ${ }^{198}$ selective hydrogenation, ${ }^{199,200}$ and Suzuki-Miyaura coupling reaction. ${ }^{201}$ Compared to their NP counterparts, SAC-POMs have maximal atom utilization, together with strong and tuneable interactions between single metal atoms and POMs. We put forward SAC-POMs to be potentially efficient catalytic systems to enable both oxidative (e.g., conversion of the $-\mathrm{OH}$ group into the $-\mathrm{COOH}$ group) and reductive (e.g., $\mathrm{C}=\mathrm{O}$ hydrogenation and hydrodeoxygenation) transformations of biomass to value-added fine chemicals under mild conditions.

Finally, a deep understanding of the relationship between the catalytic performance and the chemical/electronic/structural properties of the POM-based catalysts will be of significance for biomass utilisation. It is also of high interest to develop a new generation POM-based catalytic system for biomass valorisation in the future. We hope that this review has highlighted the usefulness of POMs in catalytic biorefinery, and will encourage more researchers to delve into this exciting field.

\section{Conflicts of interest}

There are no conflicts to declare.

\section{Acknowledgements}

We thank the National University of Singapore Flagship Green Energy Program (R-279-000-553-646 and R-279-000-553-731) for financial support.

\section{Notes and references}

1 L. T. Mika, E. Csefalvay and A. Nemeth, Chem. Rev., 2018, 118, 505-613.

2 Y. Jing, Y. Guo, Q. Xia, X. Liu and Y. Wang, Chem, 2019, 5, 2520-2546.

3 S. S. Wang and G. Y. Yang, Chem. Rev., 2015, 115, 48934962.

4 I. A. Weinstock, R. E. Schreiber and R. Neumann, Chem. Rev., 2018, 118, 2680-2717. 
5 A. Enferadi-Kerenkan, T. O. Do and S. Kaliaguine, Catal. Sci. Technol., 2018, 8, 2257-2284.

6 W. P. Deng, Q. H. Zhang and Y. Wang, Dalton Trans., 2012, 41, 9817-9831.

7 J. J. Wang, J. X. Xi and Y. Q. Wang, Green Chem., 2015, 17, 737-751.

8 L. Hu, L. Lin, Z. Wu, S. Y. Zhou and S. J. Liu, Appl. Catal., $B, 2015,174,225-243$.

9 Z. H. Zhang and G. W. Huber, Chem. Soc. Rev., 2018, 47, 1351-1390.

10 M. Wang, J. P. Ma, H. F. Liu, N. C. Luo, Z. T. Zhao and F. Wang, ACS Catal., 2018, 8, 2129-2165.

11 D. A. Bulushev and J. R. H. Ross, ChemSusChem, 2018, 11, 821-836.

12 N. Narkhede, S. Singh and A. Patel, Green Chem., 2015, 17, 89-107.

13 A. F. Lee, J. A. Bennett, J. C. Manayil and K. Wilson, Chem. Soc. Rev., 2014, 43, 7887-7916.

14 F. Su and Y. H. Guo, Green Chem., 2014, 16, 2934-2957.

15 M. Besson, P. Gallezot and C. Pinel, Chem. Rev., 2014, 114, 1827-1870.

16 H. Li, Z. Fang, R. L. Smith and S. Yang, Prog. Energy Combust. Sci., 2016, 55, 98-194.

17 C. Chatterjee, F. Pong and A. Sen, Green Chem., 2015, 17, 40-71.

18 R. De Clercq, M. Dusselier and B. F. Sels, Green Chem., 2017, 19, 5012-5040.

19 A. Shrotri, H. Kobayashi and A. Fukuoka, Acc. Chem. Res., 2018, 51, 761-768.

20 C. Z. Li, X. C. Zhao, A. Q. Wang, G. W. Huber and T. Zhang, Chem. Rev., 2015, 115, 11559-11624.

21 T. F. Wang, M. W. Nolte and B. H. Shanks, Green Chem., 2014, 16, 548-572.

22 X. G. Zhang, K. Wilson and A. F. Lee, Chem. Rev., 2016, 116, 12328-12368.

23 B. Katryniok, S. Paul and F. Dumeignil, ACS Catal., 2013, 3, 1819-1834.

24 D. Sun, Y. Yamada, S. Sato and W. Ueda, Appl. Catal., B, 2016, 193, 75-92.

25 F. Guo, Z. Fang, C. C. Xu and R. L. Smith, Jr., Prog. Energy Combust. Sci., 2012, 38, 672-690.

26 Y. B. Huang and Y. Fu, Green Chem., 2013, 15, 1095-1111.

27 L. Vilcocq, P. C. Castilho, F. Carvalheiro and L. C. Duarte, ChemSusChem, 2014, 7, 1010-1019.

28 A. M. Ruppert, K. Weinberg and R. Palkovits, Angew. Chem., Int. Ed., 2012, 51, 2564-2601.

29 Y. Nakagawa, S. Liu, M. Tamura and K. Tomishige, ChemSusChem, 2015, 8, 1114-1132.

30 S. Kim, E. E. Kwon, Y. T. Kim, S. Jung, H. J. Kim, G. W. Huber and J. Lee, Green Chem., 2019, 21, 3715-3743.

31 K.-i. Shimizu and A. Satsuma, Energy Environ. Sci., 2011, 4, 3140-3153.

32 P. Sudarsanam, R. Zhong, S. Van den Bosch, S. M. Coman, V. I. Parvulescu and B. F. Sels, Chem. Soc. Rev., 2018, 47, 8349-8402.

33 Y. Zhou, G. J. Chen, Z. Y. Long and J. Wang, RSC Adv., 2014, 4, 42092-42113.
34 R. J. van Putten, J. C. van der Waal, E. de Jong, C. B. Rasrendra, H. J. Heeres and J. G. de Vries, Chem. Rev., 2013, 113, 1499-1597.

35 S. S. Chen, T. Maneerung, D. C. W. Tsang, Y. S. Ok and C.-H. Wang, Chem. Eng. J., 2017, 328, 246-273.

36 B. Agarwal, K. Kailasam, R. S. Sangwan and S. Elumalai, Renewable Sustainable Energy Rev., 2018, 82, 2408-2425.

37 C. Xu, E. Paone, D. Rodriguez-Padron, R. Luque and F. Mauriello, Chem. Soc. Rev., 2020, 49, 4273-4306.

38 J. J. Bozell and G. R. Petersen, Green Chem., 2010, 12, 539554.

39 Y. Ogasawara, S. Itagaki, K. Yamaguchi and N. Mizuno, ChemSusChem, 2011, 4, 519-525.

40 M. X. Cheng, T. Shi, H. Y. Guan, S. T. Wang, X. H. Wang and Z. J. Jiang, Appl. Catal., B, 2011, 107, 104-109.

41 M. Klein, A. Varvak, E. Segal, B. Markovsky, I. N. Pulidindi, N. Perkas and A. Gedanken, Green Chem., 2015, 17, 2418-2425.

42 S. Zhao, M. X. Cheng, J. Z. Li, J. Tian and X. H. Wang, Chem. Commun., 2011, 47, 2176-2178.

43 X. Y. Zhang, D. Zhang, Z. Sun, L. F. Xue, X. H. Wang and Z. Jiang, Appl. Catal., B, 2016, 196, 50-56.

44 Y. M. Zhang, V. Degirmenci, C. Li and E. J. M. Hensen, ChemSusChem, 2011, 4, 59-64.

45 F. N. D. C. Gomes, F. M. T. Mendes and M. M. V. M. Souza, Catal. Today, 2017, 279, 296-304.

46 Z. Sun, L. F. Xue, S. T. Wang, X. H. Wang and J. Y. Shi, Green Chem., 2016, 18, 742-752.

47 C. H. Song, S. J. Liu, X. W. Peng, J. X. Long, W. Y. Lou and X. H. Li, ChemSusChem, 2016, 9, 3307-3316.

48 X. Y. Zhang, Y. Li, L. F. Xue, S. T. Wang, X. H. Wang and Z. J. Jiang, ACS Sustainable Chem. Eng., 2018, 6, 165-176.

49 B. S. Rao, P. K. Kumari, D. D. Lakshmi and N. Lingaiah, Catal. Today, 2018, 309, 269-275.

50 M. M. Wang, L. C. Peng, X. Y. Gao, L. He and J. H. Zhang, Sustainable Energy Fuels, 2020, 4, 1383-1395.

51 Z. Sun, S. T. Wang, X. H. Wang and Z. J. Jiang, Fuel, 2016, 164, 262-266.

52 X. Y. Zhang, X. Y. Zhang, N. Y. Sun, S. T. Wang, X. H. Wang and Z. J. Jiang, Renewable Energy, 2019, 141, 802-813.

53 F. Rataboul and N. Essayem, Ind. Eng. Chem. Res., 2011, 50, 799-805.

54 S. Q. Zhao, G. Z. Xu, C. Chang, S. Q. Fang, Z. Liu and F. G. Du, Catalysts, 2015, 5, 1897-1910.

55 Z. Sun, M. X. Cheng, H. C. Li, T. Shi, M. J. Yuan, X. H. Wang and Z. J. Jiang, RSC Adv., 2012, 2, 9058-9065.

56 S. Q. Zhou, X. M. Yang, Y. L. Zhang, L. Y. Jiang, L. P. Zhou, T. L. Lu and Y. L. Su, Cellulose, 2019, 26, 9135-9147.

57 Y. X. Zhang, X. L. Chen, X. Lyu, G. L. Zhao, T. T. Zhao, L. J. Han and W. H. Xiao, J. Cleaner Prod., 2019, 215, 712-720.

58 P. F. Pinheiro, D. M. Chaves and M. J. da Silva, Cellulose, 2019, 26, 7953-7969.

59 X. Y. Li, X. B. Lu, S. X. Nie, M. Liang, Z. H. Yu, B. Y. Duan, J. X. Yang, R. Xu, L. F. Lu and C. L. Si, Ind. Crops Prod., 2020, 145, 112154. 
60 D. Gupta, C. Mukesh and K. K. Pant, RSC Adv., 2020, 10, 705-718.

61 X. Y. Zhang, H. Z. Zhang, Y. M. Li, M. Bawa, S. T. Wang, X. H. Wang and Z. J. Jiang, Cellulose, 2018, 25, 64056419.

62 J. Tian, C. Y. Fang, M. X. Cheng and X. H. Wang, Chem. Eng. Technol., 2011, 34, 482-486.

63 K.-i. Shimizu, R. Uozumi and A. Satsuma, Catal. Commun., 2009, 10, 1849-1853.

64 Q. Zhao, L. Wang, S. Zhao, X. Wang and S. Wang, Fuel, 2011, 90, 2289-2293.

65 A. H. Jadhav, H. Kim and I. T. Hwang, Bioresour. Technol., 2013, 132, 342-350.

66 Y. Qu, C. Huang, J. Zhang and B. Chen, Bioresour. Technol., 2012, 106, 170-172.

67 X. Yi, I. Delidovich, Z. Sun, S. Wang, X. Wang and R. Palkovits, Catal. Sci. Technol., 2015, 5, 2496-2502.

68 T. Yamada, K. Kamata, E. Hayashi, M. Hara and S. Uchida, ChemCatChem, 2019, 11, 3743-3747.

69 B. Katryniok, S. Paul, M. Capron and F. Dumeignil, ChemSusChem, 2009, 2, 719-730.

70 B. Katryniok, S. Paul, V. Bellière-Baca, P. Rey and F. Dumeignil, Green Chem., 2010, 12, 2079.

71 L. Liu, X. P. Ye and J. J. Bozell, ChemSusChem, 2012, 5, 1162-1180.

72 A. Talebian-Kiakalaieh, N. A. S. Amin and H. Hezaveh, Renewable Sustainable Energy Rev., 2014, 40, 28-59.

73 L. Q. Shen, Y. H. Feng, H. B. Yin, A. L. Wang, L. B. Yu, T. S. Jiang, Y. T. Shen and Z. N. Wu, J. Ind. Eng. Chem., 2011, 17, 484-492.

74 C. Liu, R. Liu and T. F. Wang, Can. J. Chem. Eng., 2015, 93, 2177-2183.

75 R. Liu, T. F. Wang, C. Liu and Y. Jin, Chin. J. Catal., 2013, 34, 2174-2182.

76 M. H. Haider, N. F. Dummer, D. Z. Zhang, P. Miedziak, T. E. Davies, S. H. Taylor, D. J. Willock, D. W. Knight, D. Chadwick and G. J. Hutchings, J. Catal., 2012, 286, 206-213.

77 A. Talebian-Kiakalaieh, N. A. S. Amin and Z. Y. Zakaria, J. Ind. Eng. Chem., 2016, 34, 300-312.

78 H. Atia, U. Armbruster and A. Martin, Appl. Catal., A, 2011, 393, 331-339.

79 A. Talebian-Kiakalaieh and N. A. S. Amin, Chin. J. Catal., 2017, 38, 1697-1710.

80 T. L. Ma, J. F. Ding, R. Shao, W. Xu and Z. Yun, Chem. Eng. J., 2017, 316, 797-806.

81 J. F. Ding, T. L. Ma, R. Shao, W. Xu, P. F. Wang, X. Y. Song, R. F. Guan, K. L. Yeung and W. Han, New J. Chem., 2018, 42, 14271-14280.

82 J. F. Ding, T. L. Ma, M. Y. Cui, R. Shao, R. F. Guan and P. F. Wang, Mol. Catal., 2018, 461, 1-9.

83 T. Ma, Z. Yun, W. Xu, L. Chen, L. Li, J. Ding and R. Shao, Chem. Eng. J., 2016, 294, 343-352.

84 B. Viswanadham, A. Srikanth, V. P. Kumar and K. V. R. Chary, J. Nanosci. Nanotechnol., 2015, 15, 5391-5402.
85 S. Suganuma, T. Hisazumi, K. Taruya, E. Tsuji and N. Katada, Mol. Catal., 2018, 449, 85-92.

86 X. F. Liu and R. Wang, Int. J. Chem. Eng., 2018, 316939.

87 Z. H. Wang and Q. W. Chen, Green Chem., 2016, 18, 58845889.

88 P. H. Che, F. Lu, J. J. Zhang, Y. Z. Huang, X. Nie, J. Gao and J. Xu, Bioresour. Technol., 2012, 119, 433-436.

89 L. Bing, Z. H. Zhang and K. J. Deng, Ind. Eng. Chem. Res., 2012, 51, 15331-15336.

90 S. G. Wang, Z. H. Zhang, B. Liu and J. L. Li, Catal. Sci. Technol., 2013, 3, 2104-2112.

91 A. Q. Liu, B. Liu, Y. M. Wang, R. S. Ren and Z. H. Zhang, Fuel, 2014, 117, 68-73.

92 Y. Yang, M. M. Abu-Omar and C. W. Hu, Appl. Energy, 2012, 99, 80-84.

93 H. L. Wang, T. S. Deng, Y. X. Wang, Y. Q. Qi, X. L. Hou and Y. L. Zhu, Bioresour. Technol., 2013, 136, 394-400.

94 K. Wilson and A. F. Lee, Catal. Sci. Technol., 2012, 2, 884897.

95 F. Su, S. An, D. Y. Song, X. H. Zhang, B. Lu and Y. H. Guo, J. Mater. Chem. A, 2014, 2, 14127-14138.

96 Zillillah, T. A. Ngu and Z. Li, Green Chem., 2014, 16, 12021210.

97 Y. Jeon, W. S. Chi, J. Hwang, D. H. Kim, J. H. Kim and Y.-G. Shul, Appl. Catal., B, 2019, 242, 51-59.

98 J. Li, X. H. Wang, W. M. Zhu and F. H. Cao, ChemSusChem, 2009, 2, 177-183.

99 S. Zhang, Y. G. Zu, Y. J. Fu, M. Luo, D. Y. Zhang and T. Efferth, Bioresour. Technol., 2010, 101, 931-936.

100 A. S. Badday, A. Z. Abdullah and K.-T. Lee, Energy, 2013, 60, 283-291.

101 Q. Zhao, H. Wang, H. W. Zheng, Z. Sun, W. Shi, S. T. Wang, X. H. Wang and Z. J. Jiang, Catal. Sci. Technol., 2013, 3, 2204-2209.

102 X. X. Han, K. K. Chen, W. Yan, C. T. Hung, L. L. Liu, P. H. Wu, K. C. Lin and S. B. Liu, Fuel, 2016, 165, 115-122.

103 X. X. Han, Y. F. He, C. T. Hung, L. L. Liu, S. J. Huang and S. B. Liu, Chem. Eng. Sci., 2013, 104, 64-72.

104 L. L. Xu, W. Li, J. L. Hu, K. X. Li, X. Yang, F. Y. Ma, Y. N. Guo, X. D. Yu and Y. H. Guo, J. Mater. Chem., 2009, 19, 8571-8579.

105 L. L. Xu, W. Li, J. L. Hu, X. Yang and Y. H. Guo, Appl. Catal., B, 2009, 90, 587-594.

106 L. L. Xu, Y. H. Wang, X. Yang, J. L. Hu, W. Li and Y. H. Guo, Green Chem., 2009, 11, 314-317.

107 C. F. Oliveira, L. M. Dezaneti, F. A. C. Garcia, J. L. de Macedo, J. A. Dias, S. C. L. Dias and K. S. P. Alvim, Appl. Catal., A, 2010, 372, 153-161.

108 K. Srilatha, T. Issariyakul, N. Lingaiah, P. S. Sai Prasad, J. Kozinski and A. K. Dalai, Energy Fuels, 2010, 24, 47484755 .

109 K. Srilatha, C. Ramesh Kumar, B. L. A. Prabhavathi Devi, R. B. N. Prasad, P. S. Sai Prasad and N. Lingaiah, Catal. Sci. Technol., 2011, 1, 662-668.

110 A. S. Badday, A. Z. Abdullah and K.-T. Lee, Appl. Energy, 2013, 105, 380-388. 
111 F. Su, L. Ma, Y. H. Guo and W. Li, Catal. Sci. Technol., 2012, 2, 2367-2374.

112 O. d. S. Lacerda, R. M. Cavalcanti, T. M. d. Matos, R. S. Angélica, G. N. da Rocha Filho and I. d. C. L. Barros, Fuel, 2013, 108, 604-611.

113 K. Y. Nandiwale and V. V. Bokade, Ind. Eng. Chem. Res., 2014, 53, 18690-18698.

114 J. Alcañiz-Monge, G. Trautwein and J. P. Marco-Lozar, Appl. Catal., A, 2013, 468, 432-441.

115 A. S. Badday, A. Z. Abdullah and K.-T. Lee, Renewable Energy, 2014, 62, 10-17.

116 A. Patel and N. Narkhede, Energy Fuels, 2012, 26, 60256032.

117 N. Narkhede and A. Patel, Ind. Eng. Chem. Res., 2013, 52, 13637-13644.

118 V. Brahmkhatri and A. Patel, Appl. Catal., A, 2011, 403, 161-172.

119 N. Narkhede, V. Brahmkhatri and A. Patel, Fuel, 2014, 135, 253-261.

120 C. Baroi and A. K. Dalai, Catal. Today, 2013, 207, 74-85.

121 V. Brahmkhatri and A. Patel, Ind. Eng. Chem. Res., 2011, 50, 6620-6628.

122 V. Brahmkhatri and A. Patel, Fuel, 2012, 102, 72-77.

123 A. Patel and N. Narkhede, Catal. Sci. Technol., 2013, 3, 3317-3325.

124 W. L. Xie and F. Wan, Chem. Eng. J., 2019, 365, 40-50.

125 F. Su, Q. Y. Wu, D. Y. Song, X. H. Zhang, M. Wang and Y. H. Guo, J. Mater. Chem. A, 2013, 1, 13209-13221.

126 D. Y. Song, S. An, Y. N. Sun and Y. H. Guo, J. Catal., 2016, 333, 184-199.

127 K. Y. Nandiwale, S. K. Sonar, P. S. Niphadkar, P. N. Joshi, S. S. Deshpande, V. S. Patil and V. V. Bokade, Appl. Catal., A, 2013, 460-461, 90-98.

128 K. Yan, G. S. Wu, J. L. Wen and A. C. Chen, Catal. Commun., 2013, 34, 58-63.

129 F. Su, L. Ma, D. Y. Song, X. H. Zhang and Y. H. Guo, Green Chem., 2013, 15, 885-890.

130 T. M. Guo, M. Qiu and X. H. Qi, Appl. Catal., A, 2019, 572, 168-175.

131 P. L. Arias, J. A. Cecilia, I. Gandarias, J. Iglesias, M. L. Granados, R. Mariscal, G. Morales, R. Moreno-Tost and P. Maireles-Torres, Catal. Sci. Technol., 2020, 10, 2721-2757.

132 X. Chen, Y. Liu and J. W. Wu, Mol. Catal., 2020, 483, 110716.

133 P. Preuster and J. Albert, Energy Technol., 2018, 6, 501509.

134 R. Wolfel, N. Taccardi, A. Bosmann and P. Wasserscheid, Green Chem., 2011, 13, 2759-2763.

135 J. Albert, D. Luders, A. Bosmann, D. M. Guldi and P. Wasserscheid, Green Chem., 2014, 16, 226-237.

136 J. Li, D. J. Ding, L. Deng, Q. X. Guo and Y. Fu, ChemSusChem, 2012, 5, 1313-1318.

137 T. Lu, M. G. Niu, Y. C. Hou, W. Z. Wu, S. H. Ren and F. Yang, Green Chem., 2016, 18, 4725-4732.

138 J. Albert, R. Wolfel, A. Bosmann and P. Wasserscheid, Energy Environ. Sci., 2012, 5, 7956-7962.
139 J. Albert and P. Wasserscheid, Green Chem., 2015, 17, 5164-5171.

140 J. L. Xu, H. Y. Zhang, Y. F. Zhao, Z. Z. Yang, B. Yu, H. J. Xu and Z. M. Liu, Green Chem., 2014, 16, 49314935.

141 J. Reichert, B. Brunner, A. Jess, P. Wasserscheid and J. Albert, Energy Environ. Sci., 2015, 8, 2985-2990.

142 J. Albert, Faraday Discuss., 2017, 202, 99-109.

143 D. Voss, H. Pickel and J. Albert, ACS Sustainable Chem. Eng., 2019, 7, 9754-9762.

144 J. Z. Zhang, M. Sun, X. Liu and Y. Han, Catal. Today, 2014, 233, 77-82.

145 J. Albert, A. Jess, C. Kern, F. Pöhlmann, K. Glowienka and P. Wasserscheid, ACS Sustainable Chem. Eng., 2016, 4, 5078-5086.

146 N. V. Gromov, O. P. Taran, I. V. Delidovich, A. V. Pestunov, Y. A. Rodikova, D. A. Yatsenko, E. G. Zhizhina and V. N. Parmon, Catal. Today, 2016, 278, 74-81.

147 M. Dusselier and B. F. Sels, in Selective Catalysis for Renewable Feedstocks and Chemicals, ed. K. M. Nicholas, 2014, vol. 353, pp. 85-125.

148 J. Z. Zhang, X. Liu, M. Sun, X. H. Ma and Y. Han, ACS Catal., 2012, 2, 1698-1702.

149 M. L. Tao, X. Yi, I. Delidovich, R. Palkovits, J. Y. Shi and X. H. Wang, ChemSusChem, 2015, 8, 4195-4201.

150 M. L. Tao, N. Y. Sun, Y. M. Li, T. Tong, M. Wielicako, S. T. Wang and X. H. Wang, J. Mater. Chem. A, 2017, 5, 8325-8333.

151 M. L. Tao, D. Zhang, X. Deng, X. Y. Li, J. Y. Shi and X. H. Wang, Chem. Commun., 2016, 52, 3332-3335.

152 M. L. Tao, D. Zhang, H. Y. Guan, G. H. Huang and X. H. Wang, Sci. Rep., 2016, 6, 29840.

153 X. K. Li and Y. G. Zhang, ACS Catal., 2016, 6, 2785-2791.

154 J. H. Lan, J. C. Lin, Z. Q. Chen and G. H. Yin, ACS Catal., 2015, 5, 2035-2041.

155 L. Hu, L. Lin, Z. Wu, S. Y. Zhou and S. J. Liu, Renewable Sustainable Energy. Rev., 2017, 74, 230-257.

156 N. Yan, C. Zhao, C. Luo, P. J. Dyson, H. C. Liu and Y. Kou, J. Am. Chem. Soc., 2006, 128, 8714-8715.

157 C. Luo, S. Wang and H. C. Liu, Angew. Chem., Int. Ed., 2007, 46, 7636-7639.

158 A. Fukuoka and P. L. Dhepe, Angew. Chem., Int. Ed., 2006, 45, 5161-5163.

159 J. Geboers, S. Van de Vyver, K. Carpentier, K. de Blochouse, P. Jacobs and B. Sels, Chem. Commun., 2010, 46, 3577-3579.

160 J. Geboers, S. Van de Vyver, K. Carpentier, P. Jacobs and B. Sels, Green Chem., 2011, 13, 2167-2174.

161 N. V. Gromov, T. B. Medvedeva, O. P. Taran, M. N. Timofeeva, O. Said-Aizpuru, V. N. Panchenko, E. Y. Gerasimov, I. V. Kozhevnikov and V. N. Parmon, Appl. Catal., A, 2020, 595, 117489.

162 M. Liu, W. P. Deng, Q. H. Zhang, Y. L. Wang and Y. Wang, Chem. Commun., 2011, 47, 9717-9719.

163 R. Palkovits, K. Tajvidi, A. M. Ruppert and J. Procelewska, Chem. Commun., 2011, 47, 576-578. 
164 J. Chen, S. P. Wang, J. Huang, L. M. Chen, L. L. Ma and X. Huang, ChemSusChem, 2013, 6, 1545-1555.

165 B. Op de Beeck, J. Geboers, S. Van de Vyver, J. Van Lishout, J. Snelders, W. J. Huijgen, C. M. Courtin, P. A. Jacobs and B. F. Sels, ChemSusChem, 2013, 6, 199208.

166 N. García-Bosch, C. Especel, A. G. Ruiz and I. RodríguezRamos, Catal. Today, 2020, 357, 113-121.

167 Z. J. Tai, J. Y. Zhang, A. Q. Wang, J. F. Pang, M. Y. Zheng and T. Zhang, ChemSusChem, 2013, 6, 652-658.

168 Z. J. Tai, J. Y. Zhang, A. Q. Wang, M. Y. Zheng and T. Zhang, Chem. Commun., 2012, 48, 7052-7054.

169 A. Q. Wang and T. Zhang, Acc. Chem. Res., 2013, 46, 13771386.

170 M. Y. Zheng, J. F. Pang, R. Y. Sun, A. Q. Wang and T. Zhang, ACS Catal., 2017, 7, 1939-1954.

171 M. Almohalla, I. Rodríguez-Ramos, L. S. Ribeiro, J. J. M. Órfão, M. F. R. Pereira and A. Guerrero-Ruiz, Catal. Today, 2018, 301, 65-71.

172 A. B. Gawade, M. S. Tiwari and G. D. Yadav, ACS Sustainable Chem. Eng., 2016, 4, 4113-4123.

173 S. H. Zhu, Y. L. Cen, J. Guo, J. C. Chai, J. G. Wang and W. B. Fan, Green Chem., 2016, 18, 5667-5675.

174 M. Balaraju, V. Rekha, P. S. S. Prasad, B. L. A. P. Devi, R. B. N. Prasad and N. Lingaiah, Appl. Catal., A, 2009, 354, 82-87.

175 S. H. Zhu, X. Q. Gao, Y. L. Zhu, Y. F. Zhu, X. M. Xiang, C. X. Hu and Y. W. Li, Appl. Catal., B, 2013, 140-141, 60-67.

176 S. H. Zhu, Y. N. Qiu, Y. L. Zhu, S. L. Hao, H. Y. Zheng and Y. W. Li, Catal. Today, 2013, 212, 120-126.

177 S. H. Zhu, Y. L. Zhu, S. Hao, H. Y. Zheng, T. Mo and Y. W. Li, Green Chem., 2012, 14, 2607-2616.

178 S. S. Priya, V. P. Kumar, M. L. Kantam, S. K. Bhargava, S. Periasamy and K. V. R. Chary, Appl. Catal., A, 2015, 498, 88-98.

179 C. T. Q. Mai and F. T. T. Ng, Catal. Today, 2017, 291, 195203.

180 Y. Nakagawa and K. Tomishige, Catal. Sci. Technol., 2011, 1, 179-190.

181 D. S. Park, B. K. Kwak, N. D. Kim, J. R. Park, J.-H. Cho, S. Oh and J. Yi, ChemCatChem, 2012, 4, 836-843.

182 A. Alhanash, E. F. Kozhevnikova and I. V. Kozhevnikov, Appl. Catal., A, 2010, 378, 11-18.
183 J. Z. Zhang, X. Liu, M. N. Hedhili, Y. H. Zhu and Y. Han, ChemCatChem, 2011, 3, 1294-1298.

184 D. L. An, A. H. Ye, W. P. Deng, Q. H. Zhang and Y. Wang, Chem. - Eur. J., 2012, 18, 2938-2947.

185 M. A. Alotaibi, E. F. Kozhevnikova and I. V. Kozhevnikov, Chem. Commun., 2012, 48, 7194-7196.

186 K. Alharbi, E. F. Kozhevnikova and I. V. Kozhevnikov, Appl. Catal., A, 2015, 504, 457-462.

187 O. Poole, K. Alharbi, D. Belic, E. F. Kozhevnikova and I. V. Kozhevnikov, Appl. Catal., B, 2017, 202, 446-453.

188 K. Alharbi, W. Alharbi, E. F. Kozhevnikova and I. V. Kozhevnikov, ACS Catal., 2016, 6, 2067-2075.

189 M. A. Alotaibi, E. F. Kozhevnikova and I. V. Kozhevnikov, Appl. Catal., A, 2012, 447-448, 32-40.

190 O. O. Ayodele, F. A. Dawodu, D. X. Yan, J. Y. Xin and S. J. Zhang, Fuel, 2018, 221, 311-319.

191 S. Li, L. Yan, Q. Y. Liu, J. G. Liu, Q. Y. Liu, W. Fan, X. L. Zhao, X. H. Zhang, C. G. Wang, L. L. Ma and Q. Zhang, Green Chem., 2020, 22, 2889-2900.

192 B. Op de Beeck, M. Dusselier, J. Geboers, J. Holsbeek, E. Morré, S. Oswald, L. Giebeler and B. F. Sels, Energy Environ. Sci., 2015, 8, 230-240.

193 X. Q. Ma, G. Gözaydın, H. Y. Yang, W. B. Ning, X. Han, N. Y. Poon, H. Liang, N. Yan and K. Zhou, Proc. Natl. Acad. Sci. U. S. A., 2020, 117, 7719-7728.

194 Y. Z. Wang, S. Furukawa, S. Song, Q. He, H. Asakura and N. Yan, Angew. Chem., Int. Ed., 2020, 59, 2289-2293.

195 S. Song, J. G. Zhang, G. Gözaydin and N. Yan, Angew. Chem., Int. Ed., 2019, 58, 4934-4937.

196 S. P. Ding, M. J. Hülsey, J. Pérez-Ramírez and N. Yan, Joule, 2019, 3, 2897-2929.

197 M. J. Hulsey, J. G. Zhang and N. Yan, Adv. Mater., 2018, 30, e1802304.

198 M. J. Hulsey, B. Zhang, Z. R. Ma, H. Asakura, D. A. Do, W. Chen, T. Tanaka, P. Zhang, Z. L. Wu and N. Yan, Nat. Commun., 2019, 10, 1330.

199 B. Zhang, G. Sun, S. P. Ding, H. Asakura, J. Zhang, P. Sautet and N. Yan, J. Am. Chem. Soc., 2019, 141, 81858197.

200 B. Zhang, H. Asakura, J. Zhang, J. G. Zhang, S. De and N. Yan, Angew. Chem., Int. Ed., 2016, 55, 8319-8323.

201 P. L. He, B. Xu, X. B. Xu, L. Song and X. Wang, Chem. Sci., 2016, 7, 1011-1015. 